\title{
MASTER
}

WFPS: TME $-79-032$

DECEMBER 1979

$U C-20 D$

\section{CONCEPTUAL DESIGN OF A \\ COMMERCIAL TOKAMAK HYBRID REACTOR FUELING SYSTEM}

\author{
KENNETH D, MATNEY \\ HERMANN J, DONNERT \\ KANSAS STATE UNIVERSITY \\ DEPARTMENT OF NUCLEAR ENGINEERING
}

AND

TIEN-FANG YANG

MASSACHUSETTS INSTITUTE OF TECHNOLOGY

PLASMA FUSION CENTER

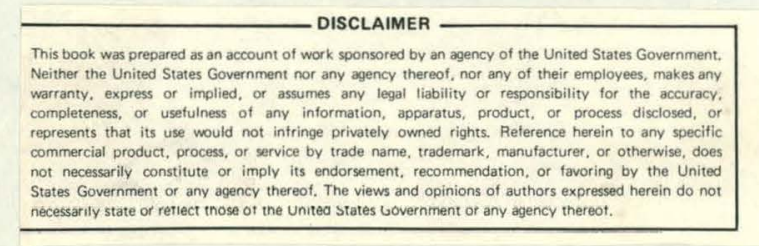

COOPERATIVE GRADUATE EDUCATION PROGRAM IN FUSION TECHNOLOGY

ADMINISTERED FOR THE U.S. DEPARTMENT OF ENERGY

BY THE WESTINGHOUSE ELECTRIC CORPORATION

CONTRACT EG-77-C-02-4237-A000 


\section{DISCLAIMER}

This report was prepared as an account of work sponsored by an agency of the United States Government. Neither the United States Government nor any agency Thereof, nor any of their employees, makes any warranty, express or implied, or assumes any legal liability or responsibility for the accuracy, completeness, or usefulness of any information, apparatus, product, or process disclosed, or represents that its use would not infringe privately owned rights. Reference herein to any specific commercial product, process, or service by trade name, trademark, manufacturer, or otherwise does not necessarily constitute or imply its endorsement, recommendation, or favoring by the United States Government or any agency thereof. The views and opinions of authors expressed herein do not necessarily state or reflect those of the United States Government or any agency thereof. 


\section{DISCLAIMER}

Portions of this document may be illegible in electronic image products. Images are produced from the best available original document. 


\section{ACKNOWLEDGEMENT}

This work was performed for the U.S. Department of Energy, under Contract EG-77-C-02-4231-A000, Cooperative Graduate Education Program in Fusion Technology. Reproduction, translation, publication, use and disposal, in whole or in part, by or for the United States Government is permitted.

Special personal thanks are being extended to Dr. Edwin E. Kintner of the U.S. Department of Energy and to Drs. Zalman Shapiro and Daniel Klein of Westinghouse Electric Corporation for their contributions in making this superb program a viable and continuing reality.

During the course of this study, the authors have become deeply indebted to Dr. Z. Shapiro, Dr. D. Klein, Dr. G. Gibson, Dr. E. W. Sucov, Mr. G. Collier, Mrs. E. Iwinski, Mr. J. Easoz, Mr. J. Selembo, and Mrs. Yvonne Harlow of Westinghouse, as well as Ms. T. Gleue, Mr. C. O'Brian, and Mrs. J. Findley of Kansas State University; their contributions, suggestions, and assistance are being acknowledged with sentiments of sincere gratitude.

In addition, the principal author (KDM) wishes to express his appreciation to his two co-authors and advisors (HJD and TFY) for their help, encouragement, and interest in this study.

\section{NOTICE}

This report was prepared as an account of work sponsored by an agency of the United States Government. Neither the United States nor any agency thereof, nor any of their employees, makes any warranty, expressed or implied, or assumes any legal liability or responsibility for any third party's use or the results of such use of any information, apparatus, product or process disclosed in this report, or represents that its use by such third party would not infringe privately owned rights.

Printed in the United States of Aillerica Available From

National Technical Infurillation Service

U.S. Department of Commerce

5285 Port Royal Road

Springfield VA 22161

NTIS Price Codes

Printed Copy: A04

Microfiche Copy: A01 
WFPS:TME-79-032

DECEMBER 1979

UC-2Od

CONCEPTUAL DESIGN OF A

COMMERCIAL TOKAMAK HYBRID REACTOR FUELING SYSTEM

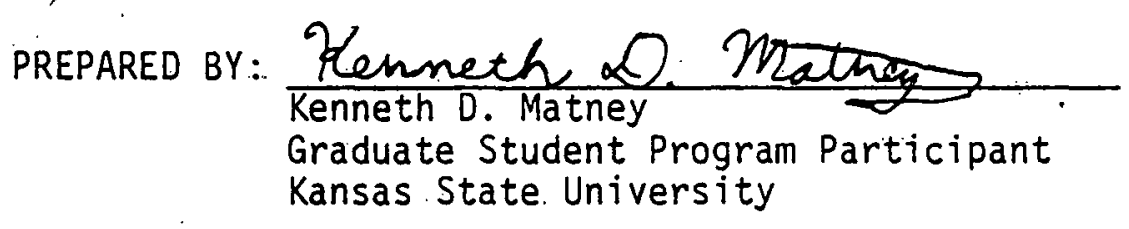

REVIEWED BY: $\frac{\text { Gibson', Manager }}{\text { Nuclear and Plasma Engineering }}$

APPROVED BY:

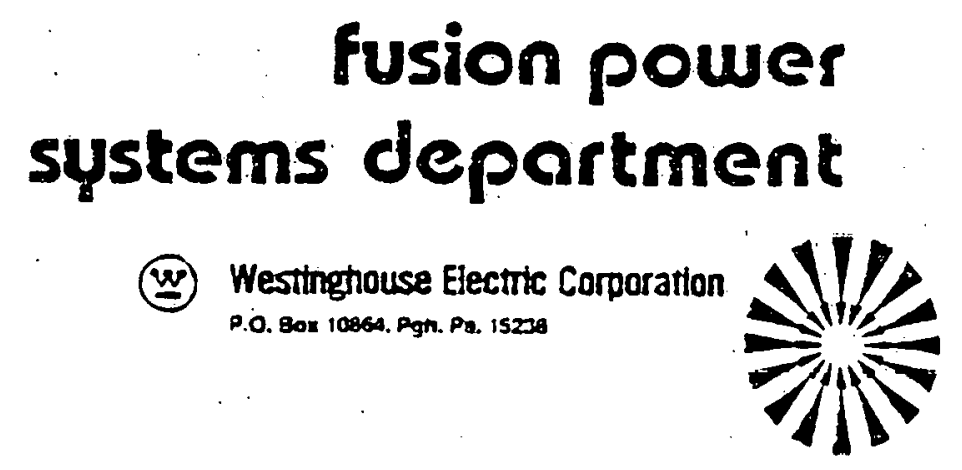


ABSTRACT

A conceptual design of a fuel injection systen for CTHR (Commercial Tokamak llybrid Reactor) is discussed. Initially, relative merits of the cold-fueling concept are compared with those of the hot-fueling concept; that is, fueling where the electron temperature is below $1 \mathrm{eV}$ is compared with iueling where the electron temperature exceeds $100 \mathrm{eV}$. It is concluded that cold fueling seems to be somewhat nore free of drawbacks than hot fueling. Possible implementation of the cold-fueling concept is exploiced via frozen-pellet injection. Several methods of achieving frozen-pellet injection are discussed and the light-gas-gun approach is chosen from these possibilities. A modified version of the ORNL Neutral Gas Shielding Model is used to simulate the pellet injection process. From this simulation, the penetration-depth dependent velocity requirement is determined. Finally, with the velocity requirement known, a gas-pressure requirenent for the proposed conceptual design is established. The cryogenic fuel-injection and fuel-handling systems are discussed. A possible way to implement the conceptual device is examined along with the attendant effects on the total system. 


\section{SUR.RAARY}

Possible Eueling concepts were examined to determine which would provide the highest probability of success for application in the CTHR (Commercial Tokamak Hybrid Reactor). Cold fueling was chosen with this idea in mind. Thereafter, the particular scheme chosen was frozen-pellet fueling, since it provides the advantage of maximum fuel-particle density. Several methods of frozen-pellet injection were studied to determine their capabilities, their experimental verification, and projections for the future. Any characteristics which might adversely affect the normal operation of the tokamak were taken into account. To this effect, the light-gas. gun was centatively chosen to provide pellet acceleration.

The ORVL Neutral Gas Shielding lodel is the basic theory used to determine the required pellet velocity. It has been modified, however, to account for operation in the comnercial temperature regine (as opposed to experimental devices with temperatures around $1 \mathrm{keV}$ ). The required pellet velocity is a function of the depth at which the pellet has disappeared as a solid entity.

From this, the pressure level and other essential estimates to be mace on the fuel injector design have been made. This leaves only the design of a fuel handing system to implement operation. The fuel handling system has been designed so that a sufficient fuel-pellet supply is produced and quality control systems may be integrated into the system at a later date.

Various ways were studied to locate the fuel injection system so as to minimize the total-system perturbation. The suggested design incorporating the fuel injector into CTHR accounts for both this espect and that of providing the shortest possible path to the plasma center. 
Summary

List of. Figures

Nomenclature and Notation : iv

$1.0 \quad$ Introduction

2.0 Fuel Scheme Modeling (Ablation Modeling) 5

3.0

Fuel Injector Design

Gas Gun Design

Fuel Handing System

Implementation into CTHR

8

3.2

3.3

Conclusions

12

5.0

References.

14

Appendix I - Solution of the System of Coupled Differential Equations

Appendix II - Determination of Pellet-Surface Mach Number 
Eigure No.

Page

1

$A$

Solution to system of coupled differential equations for case of $\xi=1000$ (reference case).

Solution to system of coupled differential equations for CTHR case $(\xi \doteq 15,301)$.

Required pellet velocity is plotred as a function of the point at which the pellet will be totally ablated, which is known as the penetration fraction or depth.

Fuel injection system for CTHR.

The shell for the fuel injector is a $1 \mathrm{~mm}$ by $30 \mathrm{~mm}$ dia disk intersected by a cylindrical shell whose thickness is $0.0254 \mathrm{~mm}$ and whose inner diameter is $6.148 \mathrm{~mm}$.

The required gas pressure, utilizing. $\mathrm{H}_{2}$ as propellent, is plotted as a function of the penetration fraction.

The required gas pressure, utilizing DT as propellent, is plotted as a function of the penetration fraction.

The fuel handling system is as diagrammed above. The liquid DT mixture enters the cylindrical chamber (above), is frozen by the liquid lie, and on the next cycle is forced out as a pellet by the entering DT $(l)$.

Incorporation of fueling systems into CTHR.

Closeup view of incorporation of pellet injector Into CTHR.

Solution of differential equation (21) for the physically realistic sound-bartier conditions. 
$u \equiv$ Required pellet velocity to achieve penetration as a solid entity to $(l / a)$, (in m/sec).

$(l / a) \equiv$ Fraction of pressure center of tokamak to whlch pellet is to penetrate; $i$. e., if $(l / a)=1$, pellet penetrates to the pressure center of the reactor.

$a$ D Distance from the outer edge of the plasma to the pressure center (in $\mathrm{m}$ ). Note that this quant1ty is taken as $0.9 \mathrm{~m}$ for CTHR.

$J \equiv$ Electron current, further defined in Eqn. 1d.

$E_{\infty} \equiv$ Thermal energy (in eV) of electrons in fusion plasma. Note: This quanticy is position dependent as 11lustrated in Eqn. le.

$E_{0} \equiv$ Thermal energy (in eV) of electrons at pellet surface. Note: This quantity has been taken as $10 \mathrm{eV}$ in Eqn. $1 \mathrm{~g}$.

$L(E) \equiv$ Electron energy loss function, approximated by Milora and Foster ${ }^{1}$ as shown in Eqn. $1 b$, (in $\mathrm{eV} \mathrm{m}^{2}$ ), where $E$ is the electron energy (in $\mathrm{eV}$ ).

$\mathrm{m} \equiv$ Mass of fuel molecule (in $\mathrm{kg}$ ).

$\mathrm{m}_{e} \equiv$ Mass of electron (in kg) $\doteq 9.109537 \times 10^{-31}$.

$\mathrm{m}_{\mathrm{h}} \equiv$ Mass of proton (in kg) $\doteq 1.673560 \times 10^{-27}$.

$m_{D} \equiv$ Mass of deuteron $(1 \mathrm{n} \mathrm{kg}) \doteq 3.344549 \times 10^{-27}$.

$\rho_{D} \equiv$ Mass density of solid deutertum $\left(\right.$ in $\left.\mathrm{kg} / \mathrm{m}^{3}\right) \doteq 2.059 \times 10^{2}$.

$Y \equiv$ Ratio of specific heats.

$e \equiv$ Charge of the electron $($ in $C) \doteq 1.6021892 \times 10^{-19}$.

$r_{p} \equiv$ Initial pellet radius $(1 \mathrm{~m})=3.073 \times 10^{-3}$.

$\because$ \#. Ratio of mass of fuel molecule to the mass of a proton.

$n_{\infty} \equiv$ Number density of electrons in the tokamak $\left(1 \mathrm{n} \mathrm{m}^{-3}\right)$. Note: This quantity is postion dependent, as in Eqn. If.

$\left\langle\mathrm{T}_{\infty}\right\rangle$ Average electron temperature of fusion plasma ( $\mathrm{In}$ eV) $=1.3 \times 10^{4}$.

$\left\langle n_{\infty}\right\rangle \equiv$ Average electron number density in fusion plasma. (in $\left.\mathrm{m}^{-3}\right)=9.8 \times 10^{19}$.

$r$ E Position varlable in fusion plasma, $i . e .,(r / a)$ is dimensionless. 


\section{NOMENCLATURE AND NOTATION (continued)}

$M \equiv$ Mach number of the ablatant.

$\hat{\rho} \equiv$ Ratio of the mass density of the ablatant. to the mass density of the ablatant at the pellet surface.

$\hat{\imath} \equiv$ Ratio of distance from pellet center to pellet radius.

$m_{s+p} \equiv$ Sum of the mass of a pellec injector shell and the mass of the fuel pellet (in $\mathrm{kg}$ ). In the present design, this is $11.947 \times 10^{-3} \mathrm{~kg}$.

$A_{s} \equiv$ Surface area of the pellet infector shell exposed to the propellent gas $\left(\right.$ in $\mathrm{m}^{2}$ ), (numerically, $\pi / 4(0: 03)^{2} \mathrm{~m}^{2}$ ).

$L \equiv$ Distance over which the fuel Injector shell and pellet are accelerated (in $\mathrm{m}$ ), taken here to be $0.30 \mathrm{~m}$.

$u_{\max } \equiv$ Maximum attainable velocity of light-gas-gun-projectile (in m/sec).

$r_{0} \equiv$ Radius of pellet as a function of time (in m).

$\rho_{0} \equiv$ Mass density of ablatant as a function of time (in $\mathrm{kg} / \mathrm{m}^{3}$ ).

$\rho_{s} \equiv$ Mass density of fuel pellet (in $\mathrm{kg} / \mathrm{m}^{3}$ ).

$v_{0} \equiv$ Speed of the ablatant (in $\mathrm{m} / \mathrm{sec}$ ). For the purposes of the decermination of the value of $\xi$ (see Eqn. 2), this quantity is taken to be $400 \mathrm{~m} / \mathrm{sec}$. 


\subsection{Introduction}

Westinghouse Fusion Power Systems Department is developing a design for a Commercial Tokamak Hybrid Reactor, referred to henceforth as CTHR. In the course of the design of the reactor, it became apparent that fueling system design must be given considerable attention. This is due to the fact that the fuel inust cross magnatic-field lines in order to effect penetration of the reacting plasma body. In spite of this, the subject of refueling mechanisms is new to the tokamak-reactor conceptual design. The idea of crossing magnetic field lines leads, bas 1cally to two concepts of fueling. These are hot fueling, wherein the fuel consists of either ionized particles or neutral particles with a high thermal energy, and cold fueling, wherein the fuel consists of particles with very small thermal energy.

In the hot fueling concept, the particle temperatures are generally above $100 \mathrm{eV}$. Some examples of this concept are cluster beams, neutral beams, and piasma guns. The primary disadvantage to using hot ionizedparticle fueling lies in the requirewent that the refueling "mixture" must have at least as high a thermal energy as the reacting body; clearly, in order to allow electrically charged Euel particles to encer and penetrate the confining magnetic field, their average energy must exceed the energy which the magnetic field was destgned to contain. The primary disadvantage to employing hot neutral-particle fueling is due to the rather small probability for interaction with the plasma; obviously, a wastefully excessive amount of fuel would have to be injected to maintain the necessary plasma density. These requirements also cause a secondary disadvantage. The interent inefficiency of heacing the fuel by an electromechanical device includes both the inefficiency of the device and the 
Carnot/Rankine inefficiencies accompanying the electrical-power generation upon which the device is operated. Thus, it is probable that cold fueling, if feasible, will be a more efficient and a safer process.

There are, basically, three different schemes for implementation of a cold-fueling concept. These are fueling by frozen. D+T pellets, squirting a jet of liquid $D+T$, and puffing gaseous $D+T$ from the surface of the reactor. All three have in common the fact that the fuel particles are unaffected by the magnetic field since they are electrically neutral. The requirement for refueling here is that the fuel must penetrate the pressure "wave" of the reacting body. Obviously, the greater the density of the fuel, the greater is the probability of penetration, provided that the fuel-injection velocity is held constant. (Remember that, upon injection into the reacting body, the fuel will tend to become very quickly ionized by the surrounding plasma.) This, effectively, justifies the concentration of the study on frozen-pellet fueling while, at least temporarily; eliminating further consideration of the liquid-jet and surface-gas schemes.

There have been many methods suggested by which pellet injection may take place and, presently, some of these will be discussed briefly. However, a far more pressing question arises to the surface. How fast, i.e., with what velocity, must a pellet be injected in order to achieve penetration of the reacting body and thereby refuel the tokamak? The model used in this paper, to describe the behavior of the pellet is the ORNL Neutral Gas Stielding Model of Foster and Milora. I The model has been modified, here, to fit more closely the realities of the CIHR temperature regime of operation. Explanation of the modification will follow in a later section. The first method for consideration is that of linear-resonance acceleration. In this method, ${ }^{2}$ a pellet of frozen $D+T$ receives a metallic coating 
and is, subsequently, electronically charged. It is then accelerated through an electric field to achieve terminal velocity. There are several disadvantages to this system, pertaining to use in a fusion-power facility, as the following illustrates:

1. The metallic coating, received by the pellet initially, enhances bremsstrahlung losses, which, in turn, increases the value of the critical nt required for fusion breakeven quite dramatically; for example, a $10 \%$ increase in bremsstrahlung would be realized from a pellet containing only $0.01 \%$ of iron.

2. Very high accelerating potentials are projected for use in such a reactor ( $100 \mathrm{MV}$ ). To assure that there is no electric-field breakdown, such a device is expected to require a length of around $100 \mathrm{m.}^{2}$ The drift tube could be expected to be enormous.

In spite of these disadvantages, however, velocity achievable by this type of system is predicted to be as high as $10^{4} \mathrm{~m} / \mathrm{sec}$, although no experimental data are available to confirm the theoretical projection.

Arother method for consideration is that of freezing a jet of liquid into a rod which is subsequenty shattered into pellets.. ${ }^{3}$ The pellets are then allowed to drift towards the target plasma without further acceleration. This method has been tested experimentally to speeds of $100 \mathrm{~m} / \mathrm{sec}$ and is expected to deliver an ultimate pellet velocity of $2000 \mathrm{~m} / \mathrm{sec}^{3}$

A third possibility for accelerating the pellet lies in striking it with 3 laser beam on one side. ${ }^{4}$ The resulting ablatant mass causes the pellet to recoil and to be accelerated into the tokamak with an estimated pellet velocity of $10^{4} \mathrm{~m} / \mathrm{sec}$. Unfortunately, no experiments have been made to test this idea. ${ }^{4}$

A fourth possibility is to accelerate the pellet mechanically through the use of rotating arbor. ${ }^{5,6}$ The primary disadvantage of this method lies in the hazard to the integrity of the vacuum caused by the rapidly moving 
arbor. This, would necessitate a protective shield for the vacuum vessel. Terminal velocity is anticipated to exceed $1000 \mathrm{~m} / \mathrm{sec}^{5}$

The final method to be discussed here is that of using a light-gas gun to accelerate the pellet. $6,7,8$. In this method, a high-pressure propellent gas strikes a disk and accelerates disk and pellet towards the reacting body. The experimental velocity achieved thus far by this method is $-330 \mathrm{~m} / \mathrm{sec},{ }^{7}$ which is higher than that for any other method studied. This method has been projected to achieve velocities of $6000 \mathrm{~m} / \mathrm{sec}^{8}$

As this is a conceptual-design paper for a possible fueling system of CTHR, it is requisite that a cholce be made of methods by which the scheme of pellet-injection may be achieved. On the basis of inherent advantages and disadvantages (including lack of experinental evidence) and projected capabilfties, a choice has been made for study in this paper. The system selected and recommended for use in the CTHR design is that of the light-gas gun for peliet injection. 


\subsection{Fuel Scheme Modeling (Ablation Modeling)}

The model chosen to simulate the behavior of the pellet in the fusion plasma is the ORNL Neutral Gas Shield Model. It is chosen for two reasons. First, the physical concepts upon which it is based seem logical; and the concomitant mathematical formulation is reasonably simple to allow numerical solution without excessive effort. Second, results of the theory in the lower-temperature regime appear to be verified by experiment. ${ }^{7}$ Thus, it is logical to apply this theory to the commercial-reactor temperature regime. All equations to be presented here are taken from reference 1 in in one form or another.

First, let us examine the equation which actually predicts the pellet velocity, u.

$$
u=K \int_{\left(\frac{l}{a}\right)}^{1}\left[\left[\frac{J}{E_{\infty}-E_{0}}\right] \int_{E_{0}}^{E_{\infty}} L(E) d E\right]^{1 / 3} \int_{E_{0}}^{E_{\infty}} \frac{d E}{L(E)} d\left(\frac{r}{a}\right) ;
$$

where

$L(E)=\left(2.35 \times 10^{15}+4 \times 10^{15} E+2 \times 10^{21} / E^{2}\right)^{-1} ;$

$K=\left(\frac{10}{3}\right)\left(\frac{\mathrm{D}}{\rho_{D}}\right)\left[E(\xi) \xi^{1 / 3}\right]^{-1}\left[\left(\frac{y-1}{2}\right)\left[\frac{E}{a_{H}}\right)\right]^{1 / 3} r_{p}^{-5 / 3} \frac{a}{\mu^{1 / 3}} ;$

$J=n_{\infty}\left[\left(\frac{e}{m_{e}}\right)\left(\frac{E_{\infty}}{3 \pi}\right)\right]^{1 / 2}$

$E_{\infty}=\frac{45}{16}<T_{\infty}>\left[1-\left(\frac{r}{a}\right)^{2}\right]^{2}$;

$n_{\infty}=\frac{3}{2}<\pi_{\infty}>\left[I-\left(\frac{r}{a}\right)^{2}\right]$; and

$E_{0} \doteq 10 \mathrm{eV}$. 
There are two terms in the above equations which are not direct physical constants or CTHR parameters. The first is $\xi$ and the second is $f(\xi)$.

The factor $\xi$ is a quantity referred to by Foster and Milora as a heating parameter and is defined thus:

$$
\xi \equiv \frac{\gamma-1}{2 \mu} \cdot e \frac{L(E)}{: m_{H}} \frac{\Sigma_{0}}{v_{0}^{3}} \mathrm{~J}
$$

where $E$ is in $\mathrm{eV}$ and $L(E)$ is in $\mathrm{eV} \mathrm{m}^{2}$.

The second factor $F(\xi)$ is defined by the following expression:

$$
f(\xi)=\int_{1}^{\infty} \hat{\rho} \mathrm{d} \hat{r}
$$

Solving this equation is obviously dependent upon the function of $\hat{t}$ that $\delta$ happens to assume. From conservation of flux, momentum flux, and energy flux principles Foster and Milora derive the following coupled differential equations for the reduced density, $\hat{\rho}$ and the Mach number, $M$ as a function of the reduced position $\mathrm{P}$ :

$$
\begin{aligned}
& \frac{d M}{d \hat{L}}=\frac{M}{1-M^{2}}\left[\xi\left(S \hat{r}^{2}\right)^{3} M^{2}\left(1+\gamma M^{2}\right)-\frac{2+(\gamma-1) M^{2}}{\hat{P}}\right] \\
& \frac{d \dot{\rho}}{d \dot{I}}=\frac{2 M^{2} \delta}{1-M^{2}}\left[\frac{1}{\hat{l}}-\xi\left(\rho \dot{P}^{2}\right)^{3}\right]
\end{aligned}
$$

Note: This last equation may be derived from equation 15 of Reference \# 1 , but does not actually appear in this form in Foster and Milora's report. See Appendix I for derivation and details of solution.

To these equations, we have the following boundary conditions:

$$
\begin{aligned}
& \text { (i) } \beta(\hat{P}=1)=1 \\
& \text { (ii) }\left.\frac{d M}{d \hat{r}}\right|_{\hat{r}=\infty}=0 \text { or } M(\hat{\varphi}=\infty)=\sqrt{5 / Y}
\end{aligned}
$$


It is this system of equations. ( $1,2,3 a$, and $3 b$ ) that must be solved in order to model the pellet ablation process. In order to solve equations (3a) and (3b) numerically, it is necessary to have $\hat{\rho}(\hat{r}=1)$ and $M(\hat{r}=1)=M_{0}$. These equations may be solved with the available information in one of two ways. The first is to guess an initial value of the Mach number and, thereupon, use a numerical integration and shoot for the appropriate solution. As little or nothing is known about the initial Mach number, this can become a great waste of computer time. To this end, another method was developed to determine the appropriate value of the initial Mach number. Due to the complex nature of the mathematics used in this method, the details are relegated to Appendix II.

Initially, equations (3a) and (3b). were solved for two cases. The first case was a reference case solved previously for $\xi=1000.1$ The second case is for the value of $\xi$ given by CTHR parameters. Comparison of the two solutions may be made by examining Figures 1 and 2 . What we shall actually compare is the value of $f(\xi)^{-1} \xi^{-1 / 3}$, for it is this constant upon which the velocity distribution will vary. In the reference case, Foster and Milora obtained a value of 1.23 for $f(\xi)^{-1} \xi^{-1 / 3}$; whereas the value obtained here is 1.156 . For details of solution, Appendix I may be consulted.

These equations were next solved simultaneously for the parameters of CTHR. A value for $f(\xi)^{-1} \xi^{-1 / 3}$ of about 1.0973 was obtained. The pellet velocity requirement as a function of the quantity (l/a) (of equation ( 1 )) is plotted in Figure 3.

Now. we are ready to consider design of the fuel injection system. 


\subsection{Fuel Injector Design}

\subsection{Gas Gun Design}

The light gas gun is the type of design chosen for the fuelinjection system of CTHR, whose pertinent plasma dimensions are given by a minor radius of $1.40 \mathrm{~m}$, an aspect ratio of 4.33 , and an elongation of 1.60. The conceptual design is shown in Figs, 4 and 5 . It is a system which is easily used in rapid-fire mode, say, one to three pellets per second. The anticipated average firing rate is one pellet per second. The size of the pellet is such that for a pellet fueling rate of three per second, the reactor will be refueled every 1.64 seconds (the plasma confinement time for CTHR). Calculations show that this is about 6.146 in diameter (assuming spherical geometry).

The final parameter required for this design is the pressure used by the light gas gun. Since the requfred pellet velocity is a function $\because$ of the penetration depth and since the required gas pressure depends on the velocity needed, the gas pressure may be expressed as a function of penetration depth.

The gas pressure as a function of injection velocity is given by the following expression: ${ }^{9}$

$P=\frac{m_{s+p}}{A_{s}} \frac{u \cdot u_{\max }}{2 L}\left(\frac{y-1}{\gamma+1}\right)\left[\left(1-\frac{u}{u_{\max }}\right)^{\frac{\gamma+1}{\gamma-1}}-1\right]$

(assuming a frictionless injection system). dunerically, with assumed parameters where $P$ is the gas pressure $(1 \mathrm{~Pa})$ and $\mathrm{u}$ is the required pellet velocity (in $\mathrm{m} / \mathrm{sec}$ ), one has for hydrogen gas:

$P=5033.7 u\left[\left(1-\frac{u}{6578.4}\right)^{-6}-1\right]$;

and for $D+T$ gas:

$P=3187.7 u\left[\left(1-\frac{u}{4166.0}\right)^{-6}-1\right]$ 
The required gas pressure is plotted as a function of the penetration fraction in Figures 6 and 7 for elemental hydrogen and a deuterium-tritium mixture, respectively.

This brings up one final question. What type of perfomance can we expect from a light-gas-gun such as that which is conceptualized here? If the performance of the gun were limited to that already achieved by others, 7 i.e., a pellet-injection speed of $330 \mathrm{~m} / \mathrm{sec}$, the pellet would disappear as a solid entity after penetrating about $25 \%$ of the distance to the pressure center (see Fig. 3): The maximum performance to be expected of a light-gas gun employed in the refueling of CTliR is determined by assuming that the maximum applicable propellent pressure is $100 \mathrm{GPa}$. Thus, the performance limit for the D+T propellent is found from Figs. 7 to 3 to. result in a penetration of about $45 \%$ of the pressure-center distance, achieved with an injection velocity of approximately $3600 \mathrm{~m} / \mathrm{sec}$. Based on Figs. 6 and 3 , the limit for the $\mathrm{H}_{2}$ propellent turns out to be somewhat higher, say a maximura penetration of about $50 \%$, corresponding to an injection velocity of approximately $5500 \mathrm{~m} / \mathrm{sec}$. The extremely high pressure assuned above is justified when one notes that this value may be decreased by a factor of 5 to 10 were this design modified such that each shell could be used only for a single shot.

\subsection{Fuel Handing System}

The fuel handling system prepares the D+T pellets and subsequently, makes them available to the fuel injection system. To make fuel handling simpler, the pellets have been given a cylindrical shape in place 
of the sphertcal one assumed earlier in this report. The net result of this is a cylinder diameter $\sqrt[3]{16 / 3}$ times the sphere's radius and a height equal to the diameter. The effects of this geometry shift on ablation are unknown but, obviously, expected to be small. [Note that the ratio of surface area to volume is increased only by about 15 percent.]

The fuel handling system works on the following principles (see Fig. 8). Initially, the D+T mixture is cooled by a liquid nitrogen stage. The next stage, which liquifies the fuel, is a liquid helium stage. These discrete steps are suggested since the pellets will be mass produced and liquid helium is more expensive than liquid nitrogen. The very cold $\mathrm{D}+\mathrm{T}$ mixture $(5$ to $10 \mathrm{~K}$ ) is injected into a mold whose temperature is maintained at $4.2 \mathrm{~K}$ by the liruid helium until the pellets are frozen. The newly formed pellets are subsequently ejected from the mold by the liquid D+T for the next cycle of pellets. Several of these pellet makers could be in operation simultaneously and quality control may be instituted if and where necessary.

Now that the fuel pellets have been formed, they may be loaded into the fuel infector mechanically. The remaining problem is to implement the system into CTHR.

\subsection{Implementation into CTHR}

For implementation into CTHR, several criteria must be taken into account:

1. The pellet must take the shortest path possible to the fusion plasma. 
2. The amount of radiation shielding used to isolate the system from the environment should be minimized within good safety practices.

3. The fuel injection system must be located at a position in the system. to make maintenance feasible.

4. Surrounding systems (and subsystems) must be affected as little as possible by the introduction of the fuel injection system.

These goals are attained as shown in Figures 9 and 10. Figure 9 illustrates the overall system and how each of 3 injector systems may be put into CTHR. In Figure 10, a closeup view is provided, to illustrate maincenance possibilities and to fllustrate better radiation-shield requirement and system implementation. As can be seen from Fig. 9, interaction of the fuel injection systems with CTHR is very limited, indeed. 


\subsection{Conclusions}

After rejection of several hot-fueling schemes because of inherent difficulties anticipated in practical implementation, the three possibilities of tokamak refueling with cold fuel were considered: liquid-fuel-jet injection, gas puffing, and frozen-pellet injection. : It was concluded that pellet fueling appeared to be the most likely of these three alternatives to succeed as a practical scheme. Several methods by which pellet fueling could be implemented into CTHR were then investigated. This led to the further conclusion that the iight-gas-gun approach entailed probably the fewest number of real drawbacks. The ORNL Neutral-Gas-Shielding-Model was used to model pellet ablation in CTHR and a required pellet injection velocity was determined as a function of required penetration-depth in the CTHR plasma. On this basis, a conceptual design for a light-gas-gun fuel-injection system for CTHR was developed and the gas-pressure requirement for the device was determined. Finally, suggested. means for implementation into the overall destgn of CTHR have been discussed.

It must be recalled, however, that the penetration-depth requirement for CTHR has not been flrmly established. This penetration-depth requirement will ultimately determine the potential feasibility of the design presented in this report. To this end, such a study is highly recommended.

In conclusion, the findings of this study are as follows:

1. If it is determinen that the required penetration depth must be $50 \%$ of the pressure center distance or more, the light-gas gun will most probably not succeed in refueling CTHR.

2. If the required penetration is between $45 \%$ and $50 \%$ of the pressure center distance, the $D+T$ propellent mixture will most likely not 
succeed in achieving the required injection velocity, but the light-gas-gun design wight be practically feasible with $\mathrm{H}_{2}$ as the propelient.

3. If the required penetration depth is between $25 \%$ and $45 \%$ of the pressure center depth, the proposed light-gas-gun injection system should be able to refuel the CTHR, with either propelient.

4. If the required penetration depth is less than $25 \%$ of the pressure center distance, the proposed scheme of light-gas gun injection will be able to achieve the necessary penetration velocity based on currently tested and proven state-of-the-art technology. 


\subsection{References}

1. "ORNL Neutral Gas Shielding Model for Pellet-Plasma Interactions," S. L. Milora and C. A. Foster, ORNL/TM-5776 (1977).

2. "Linear Resonance Acceleration of Pellets," R. G. Mills, Proceedings of the Princeton Fueling Workshop (1978) CONF-771129.

3. "Fueling by Liquid Jets," C. Bruno, Proceedings of the Princeton Fueling Workshop (1978) CONF-771129.

4. "Laser Acceleration of Reactor Fuel Pellets," F. S. Felber, Nuclear Fusion 18, 1469, (1978).

5. "ORNL Pellet Acceleration Program," C. A. Foster and S. L. Milora, Procredings of the Princeton Fueling Workshop, (1978) CONF-771129.

6. "Sumary of Fueling by Pellet Injection," L. D. Stewart, Proceedings of the Princeton Fueling Workshop, (1978) CONF-771129.

7. "Hydrogen Pellet Fueling Experiment on the ISX-A Tokamak," S. L. Milora, C. A. Foster, P. H. Edmonds, and G. L. Schmidt, ORNL/TM-6496 (19.78).

8. "A Review of Gas Gun Technology with Emphasis on fusion Fueling Applications," R. F. Flago, Proceedings of the Princeton Fueling Workshop, (1978) CONF-771129.

9. "Pneumatic Hydrogen Pellet Injection for the ISX Tokamak," S. L. Milora and C. A, Foster, ORNL/TM-6598, (1978). 


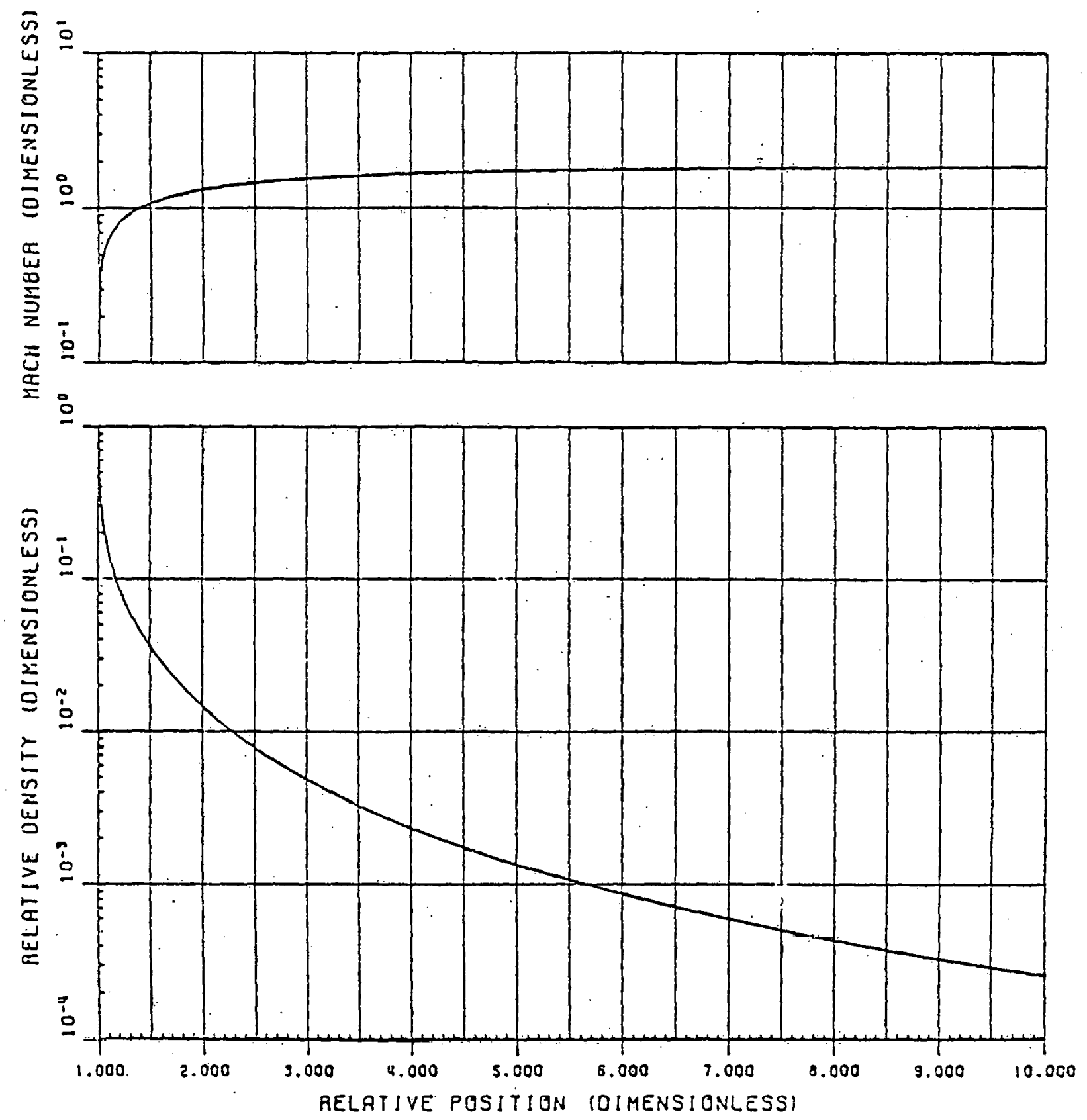

Figure 1. Solution to system of coupled differential equations for case of $\xi=1000$ (reference case - Milora and Foster 1 ). 


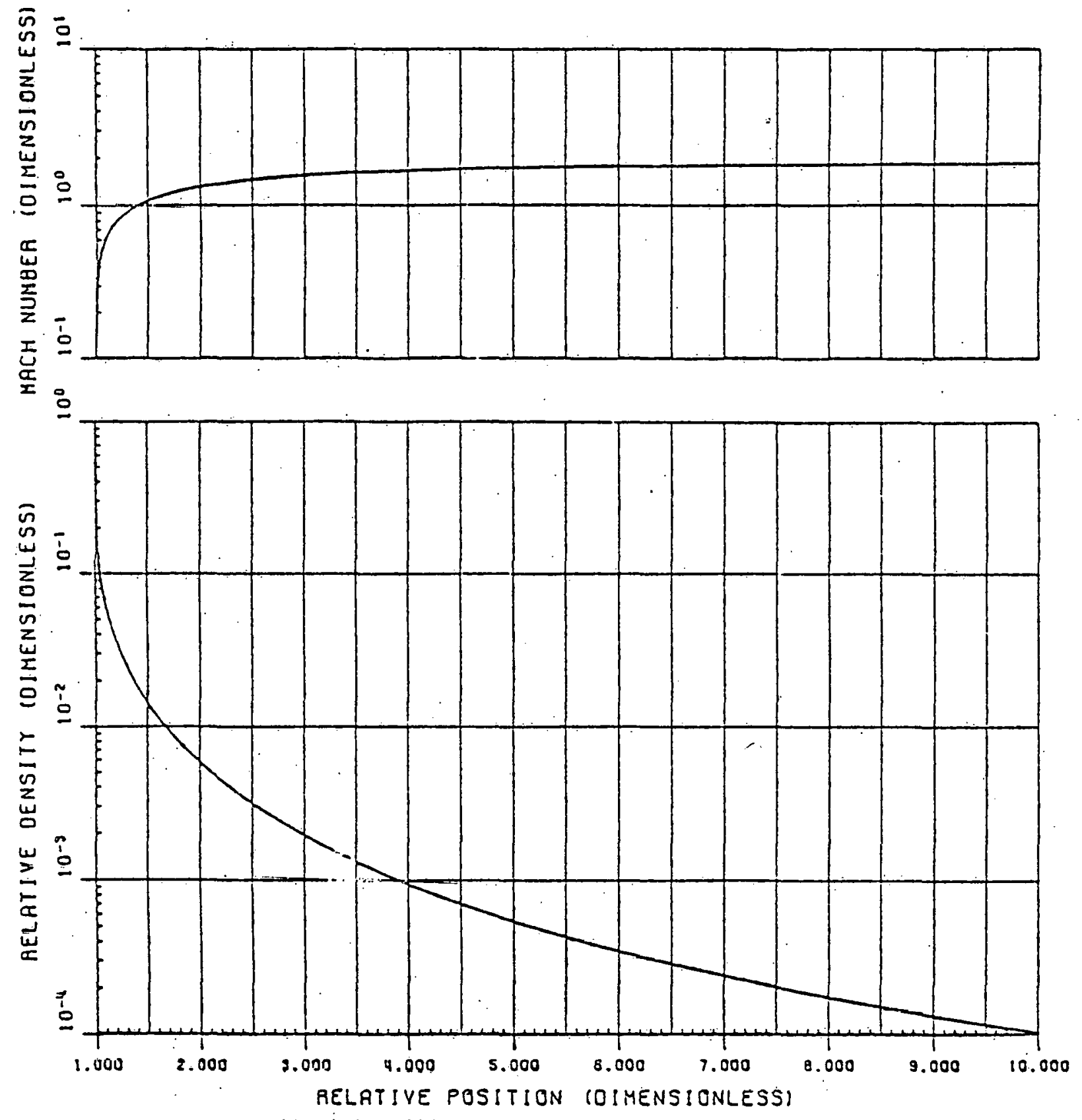

Figure 2. Solution to system of coupled differential equations for CTHR case $(\xi=15,301)$. 


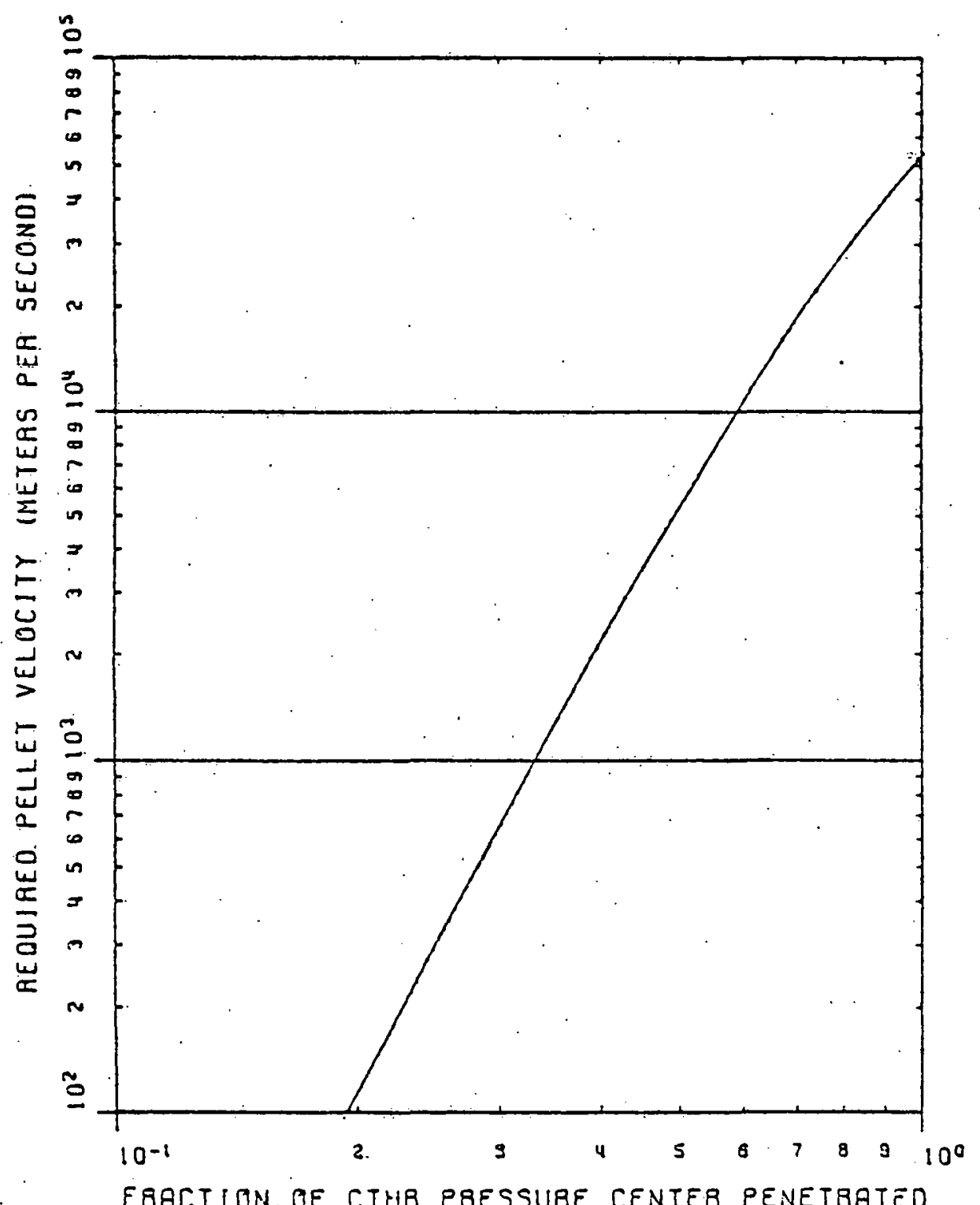

Figure 3. Required pellet velocity is plotted as a function of the puint at which the pelitet will be totally ablaced, which is known as the penetration fraction or depth. 


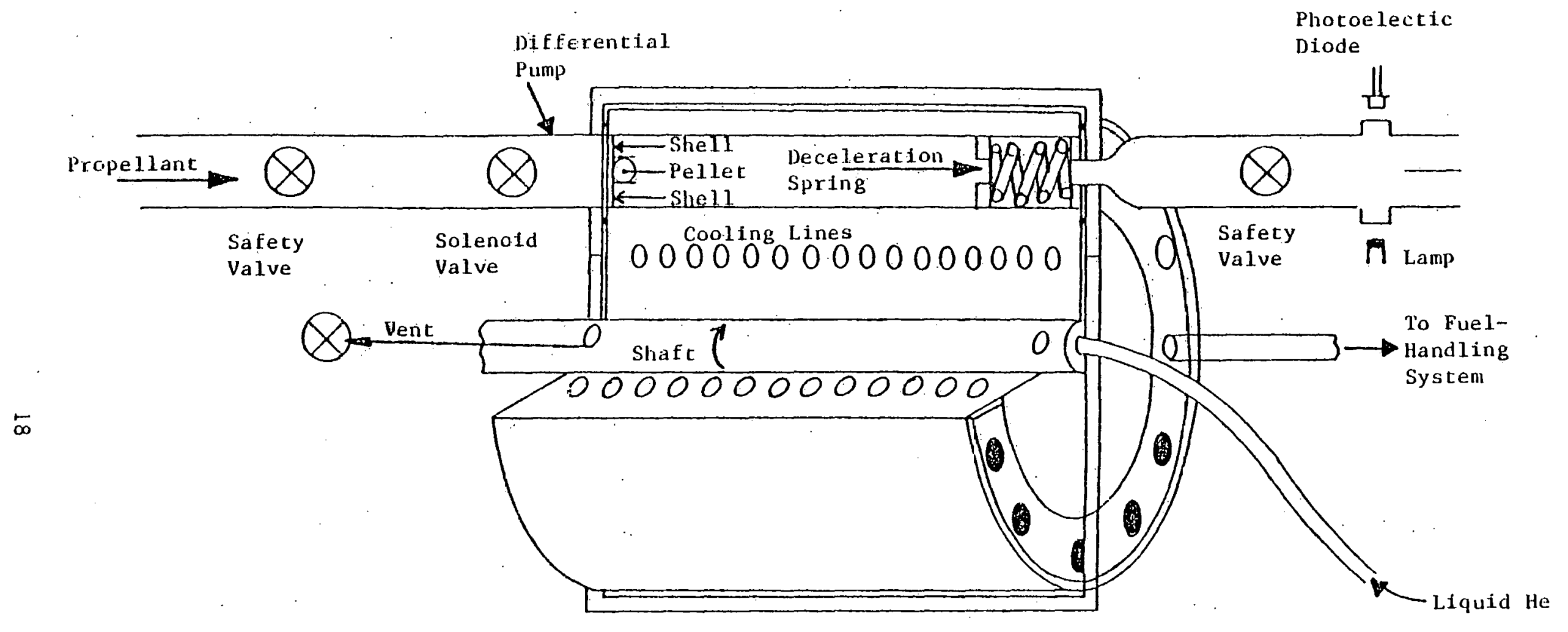

Figure 4. Fuel injection system for ClHR 


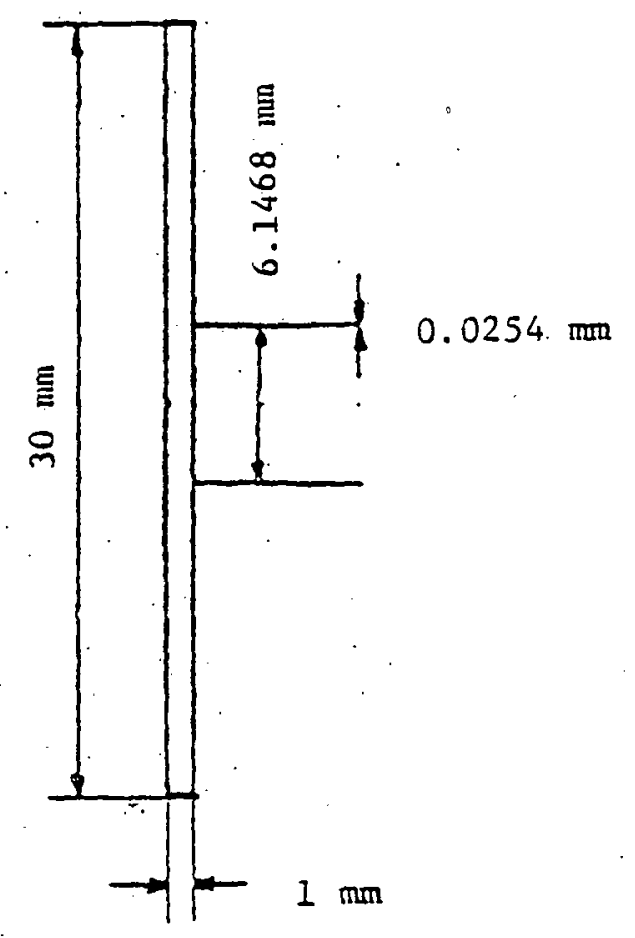
Figure 5. The shell for the fuel injector is a
lmm by $30 \mathrm{~mm}$ dia disk intersected by a cylindriral shell whose thickness is $0.0254 \mathrm{~mm}$ and whose inner diameter is 6.1648 . 


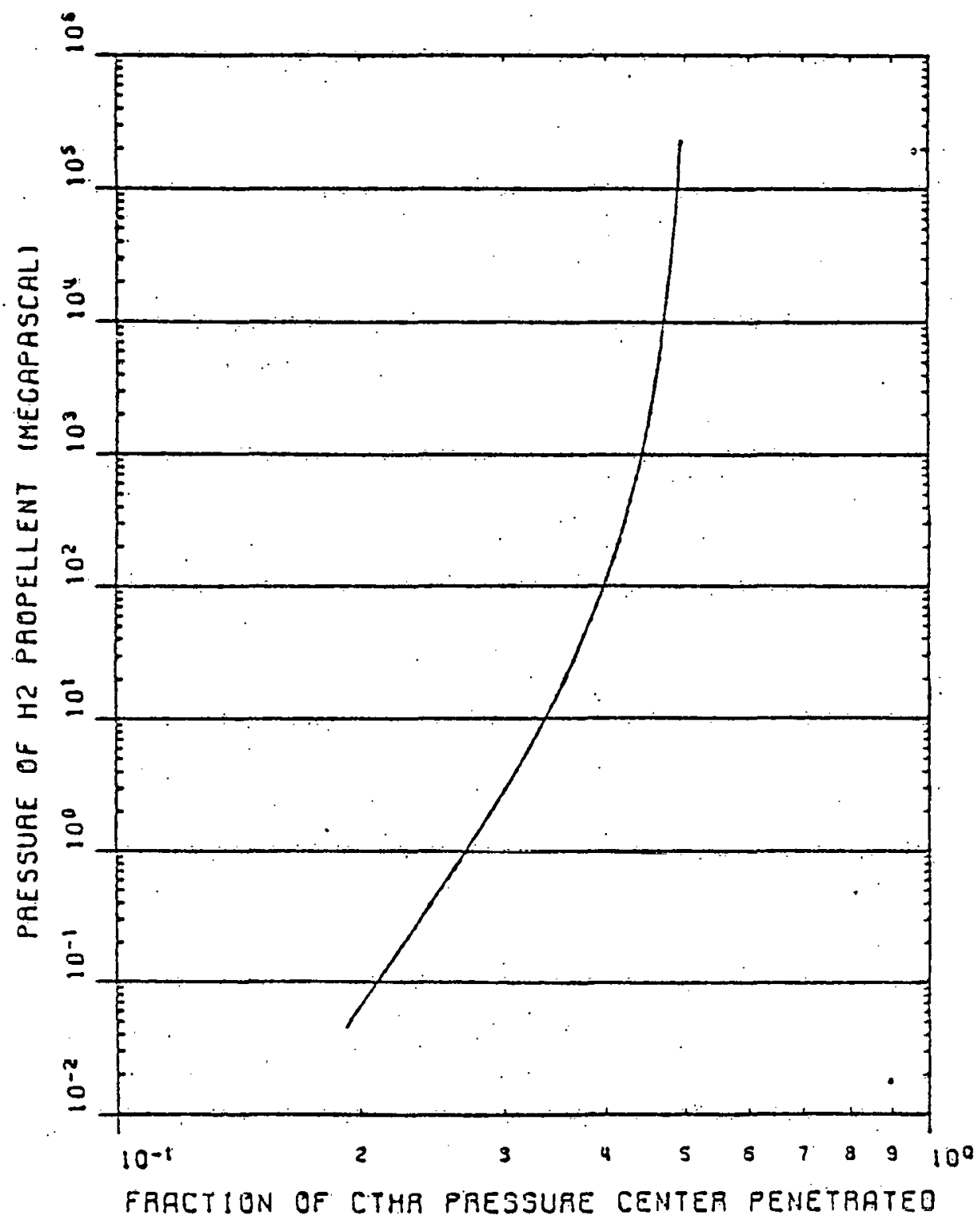

Figure 6. The required gas pressure, utilizing $\mathrm{H}_{2}$. as propellent, is plotted as a function of the penetration fraction. 


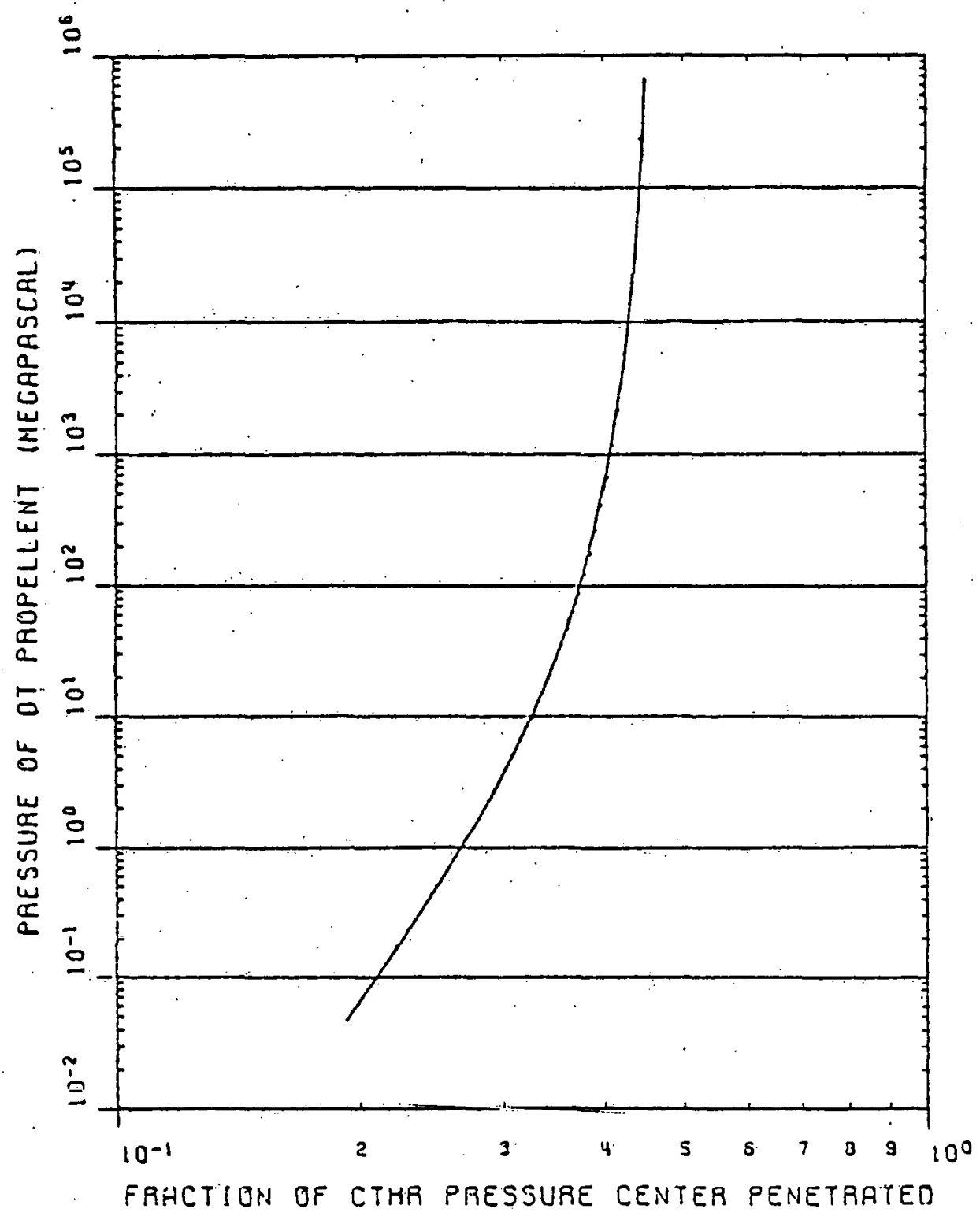

Figure 7. The required gas pressure, utilizing DT as propeliant, is plotted as a function of the penetration fraction. 


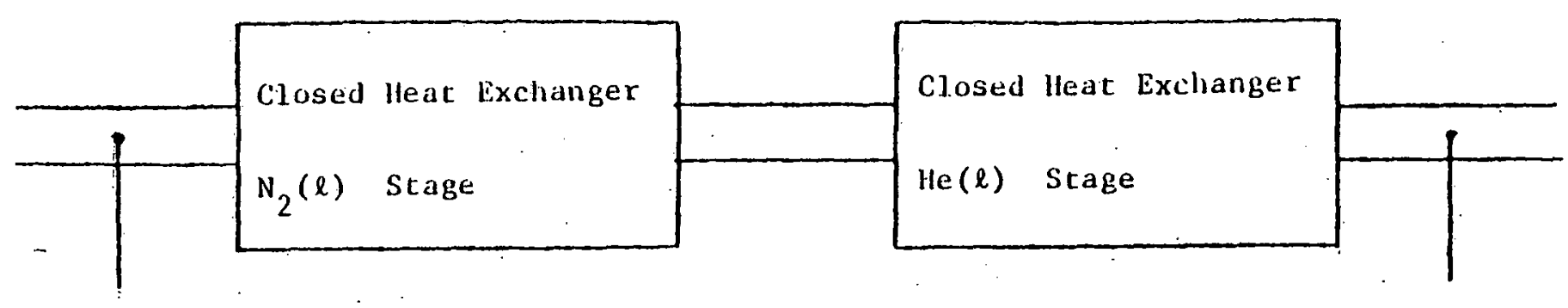

\section{Gasecus}

Liquid

Deuterium-

Deuterium-

Tritium

Tritium

Mixture

Mixture

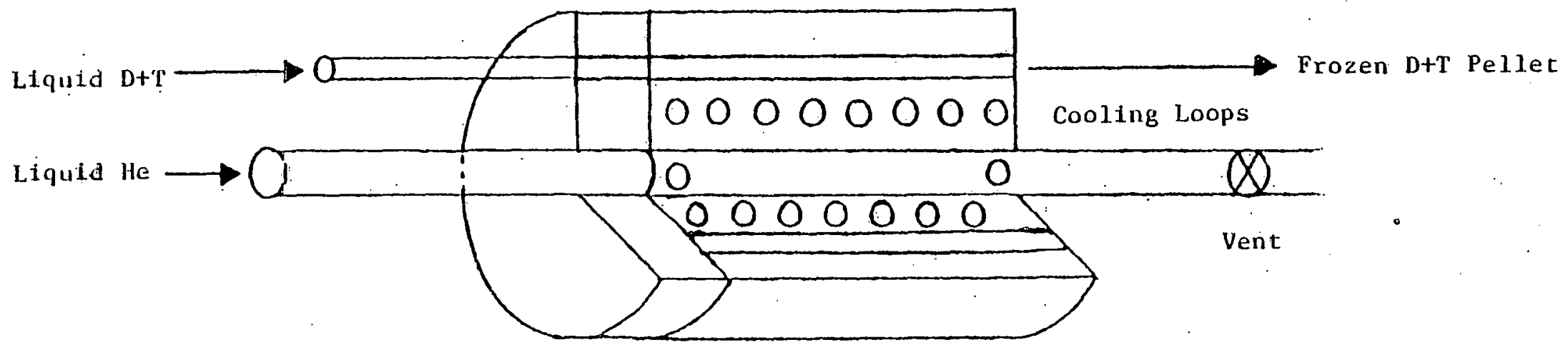

Figure 8. The fuel handling system is as diagrammed above. The liquid DT mixture enters the cylindrical chamber (above), is frozen by the liquid He, and on the next cycle is forced out as a pellet by the entering DT $(\ell)$. 


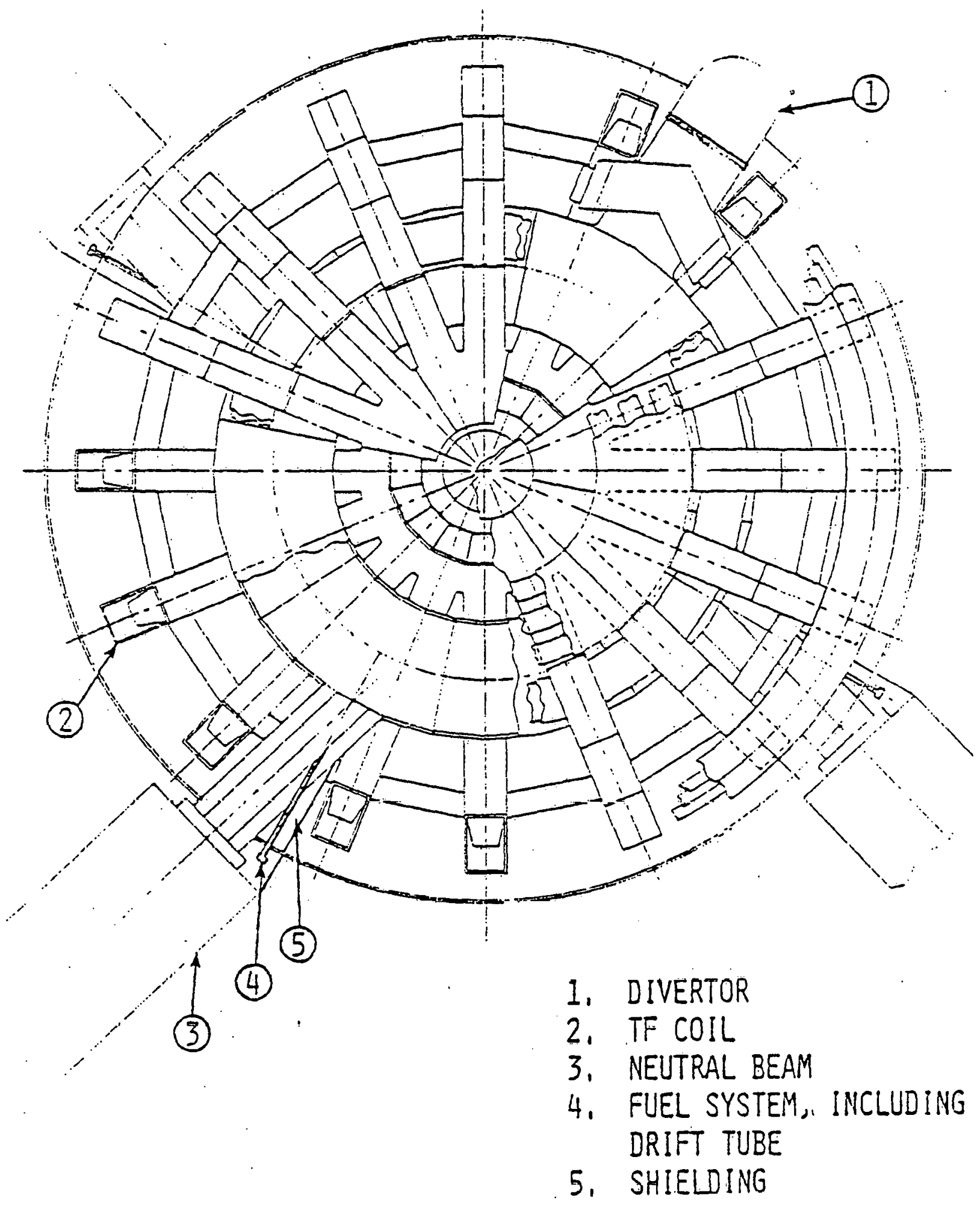

Figure 9. Incorporation of fueling systems into CTHR. 


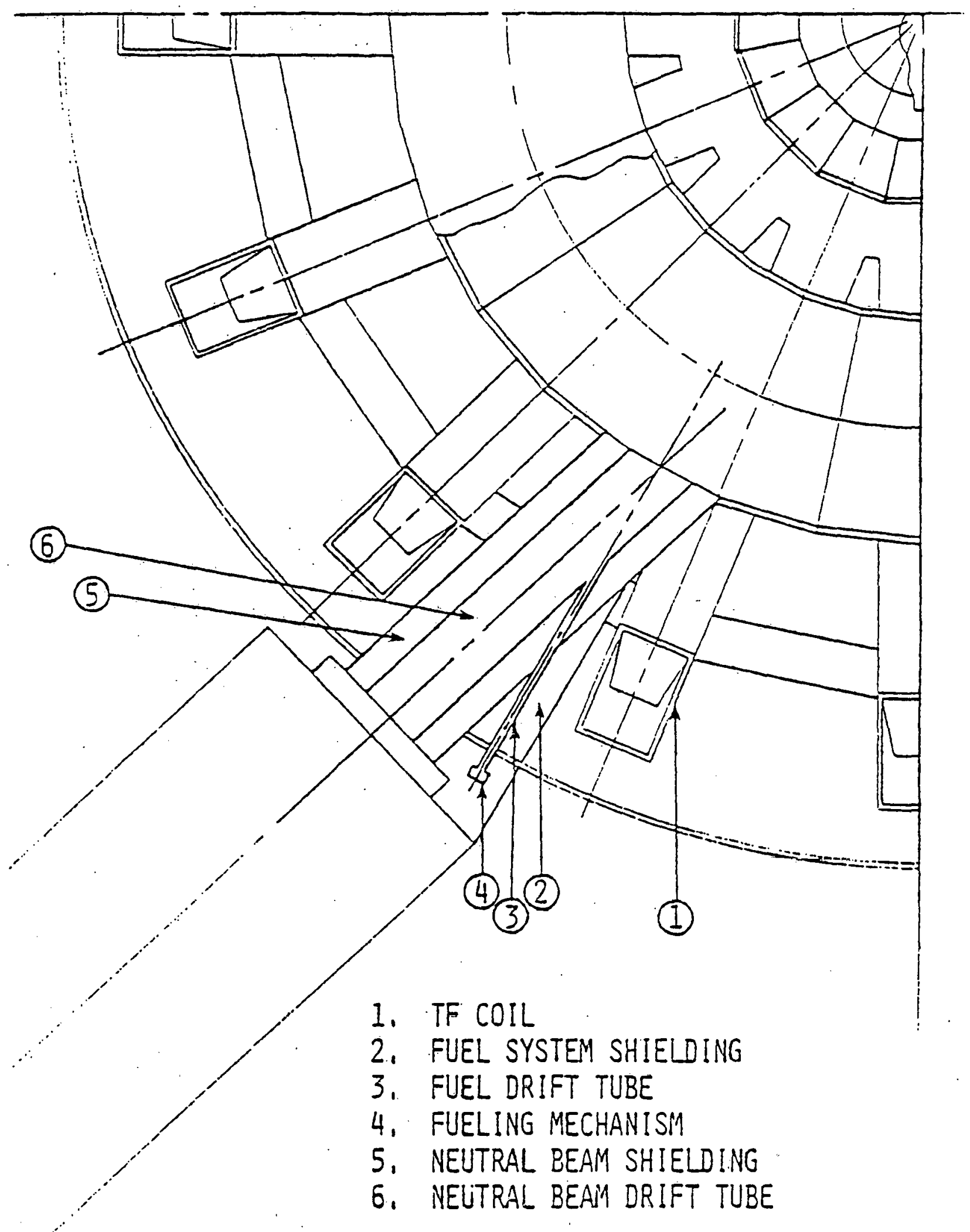

Figure 10. Closeup view of incorporation of pellet injector into CTHR. 
Appendix I. Solution of the System of Coupled Differential Equations

The set of coupled differential equations ( $C D E^{\prime} s$ ) given by Foster and Milora ${ }^{1}$ are as follows:

$$
\begin{gathered}
\left(1-Y^{2}\right) \frac{d M}{d \underline{I}}=\frac{1}{2}\left(\frac{\rho_{0}}{\rho_{S}}\right)^{3}\left|\frac{d r_{0}}{d t}\right|^{-3} \frac{e L(E)}{M} J r_{0}(\gamma-1) \delta^{3} \hat{r}^{6} M^{3}\left(\gamma M^{2}+1\right) \\
-\frac{2 M}{r}\left(1+\frac{\gamma-1}{2} M^{2}\right)
\end{gathered}
$$

$\frac{d}{d \hat{g}}\left(\hat{\rho} \hat{r}^{2}\right)^{-1}+\frac{\hat{r}^{2}}{\gamma} \frac{d}{d \hat{z}}\left(M^{2} \hat{o} \hat{r}^{4}\right)^{-1}=0$

where $\left.\xi \equiv \frac{(\gamma-1)}{2} \quad{ }_{\rho_{S}}^{\rho_{\rho}}\right)^{3} \frac{\text { e } L(E)}{m}$ J $r_{0}\left|\frac{d r_{o}}{d t}\right|^{-3}$

and where $r_{0}^{2} \rho_{0} v_{0}=-r_{0}^{2} \rho_{s} \frac{d r_{0}}{d t}$

Equations (1), (2), and (4) represent the laws of conservation of energy, momentum, and mass, respectively, and equation (3) is merely a simplifying definition.

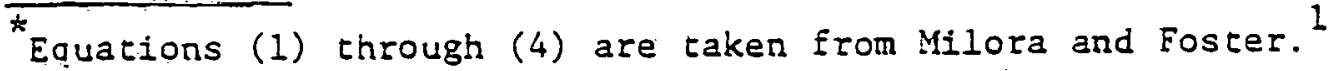


First, find an approximate value for $\xi$ valld for the commercial plasma density and temperature regime. Equation (3) may be expressed in the following form (through the use of equation (4), if $\xi$ is given by the average over the reacting body:

$$
\xi=\frac{(Y-1)}{2} \frac{e<[(E)\rangle}{m} \frac{r_{0}}{v_{0}} J^{\circ}
$$

where $\quad J=n \sqrt{\text { ekT/2ma }}$

Calculations for $\xi$ show that, for CTHR, this value is approximately

$1.53 \times 10^{4}$.

Now, derive a set of coupled differential equations solvable by computational methods wherein the solution for $\rho(r)$ may again be integrated to provide a numerical value for $\xi^{-1 / 3} \mathrm{f}(\xi)^{-1}$.

Substitution of equation (3) into equation (1) yields the following., upon rearrangement of terms:

$\frac{d M}{d Q}=\frac{M}{1-M^{2}}\left[\xi\left(\hat{\rho} \hat{q}^{2}\right)^{3} M^{2}\left(Y M^{2}+1\right)-\frac{\left(2+(y-1) M^{2}\right)}{q}\right]$

Equation (2) is somewhat more complex to solve for $\rho(r)$ but is done in the following manner. Use the chain rule to obtain the following:

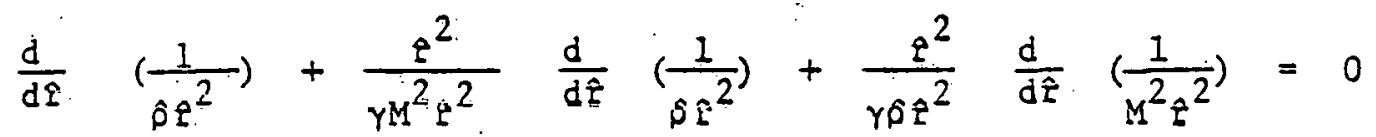

Rearranging terms:

$\frac{d}{d t}\left(\frac{1}{\rho t^{2}}\right)\left[1+\frac{1}{\gamma M^{2}}\right]+\frac{1}{Y \hat{\phi}} \quad \frac{d}{d \Phi}\left[\frac{1}{M^{2} \rho^{2}}\right]=0$

Equations (5a) and (5b) are also taken from Milora and Foster. 
Again using the chain rule yields:

$\frac{d}{d \hat{P}}\left(\frac{1}{\rho \hat{H}^{2}}\right)\left[\frac{Y M^{2}+1}{\gamma M^{2}}\right]+\frac{1}{Y \hat{\rho} M^{2}} \cdot \frac{d}{d \hat{P}}\left(\frac{1}{\hat{r}^{2}}\right)+\frac{1}{\gamma \hat{\rho} \hat{r}^{2}} \frac{d}{d \hat{P}}\left(\frac{1}{M^{2}}\right)=0$

This may be reexpressed as follows by differentiating and then multiplying the equation by $-\gamma M^{2}$ o $\hat{\mathrm{S}}^{2}$ :

$\frac{1}{\left(\hat{\rho} \hat{r}^{2}\right)} \frac{d}{d \hat{I}}\left(\hat{\rho} \hat{r}^{2}\right)\left[1+\gamma M^{2}\right]+\frac{2}{\hat{L}}+\frac{2}{M} \frac{d M}{d \hat{I}}=0$

The following results from using the chain rule of differentiation and com-. bining terms:

$\frac{d \hat{\rho}}{d \hat{I}} \cdot\left[\frac{1+Y M^{2}}{\hat{\rho}}\right]+\frac{2\left(2+Y M^{2}\right)}{\hat{I}}+\frac{2}{M} \frac{d M}{d \hat{I}}=0$

If eqn (6) is substituted into the above relationship:

$\frac{d \rho}{d \hat{f}}\left[\frac{I+\gamma M^{2}}{\delta}\right]=-\frac{2\left(2+Y M^{2}\right)}{\hat{\rho}}-\frac{2}{M}\left[\frac{M}{I-M^{2}}\left[\xi\left(\hat{\rho} \hat{r}^{2}\right)^{3} M^{2}\left(\gamma M^{2}+1\right)-\frac{2+(\gamma-1) M^{2}}{\hat{I}}\right]\right]$

Upon rearranging terms further, the following is found:

$\left(\frac{1+Y M^{2}}{\delta}\right) \frac{d \rho}{d \hat{\tau}}=-\frac{2}{1-M^{2}}\left[\xi\left(\delta \varphi^{2}\right)^{3} M^{2}\left(1+Y M^{2}\right)-\frac{2}{\hat{\varphi}}+\frac{2}{\hat{L}}\left(1-M^{2}\right)-\frac{(\gamma-1) M^{2}}{\varphi}+\frac{\gamma M^{2}}{\hat{L}}\left(1-M^{2}\right)\right]$

This may be reexpressed in the following form by combining terms:

$\left(\frac{1+Y M^{2}}{\delta}\right) \frac{d \hat{\delta}}{d \hat{r}}=-\frac{2 M^{2}}{1-M^{2}}\left[\xi\left(\hat{\rho} \hat{r}^{2}\right)^{3}\left(1+Y M^{2}\right)-\frac{2}{\hat{L}}+\frac{1}{\hat{r}}-\frac{\gamma M^{2}}{\hat{r}}\right]$

Combining terms again in the above equation yields:

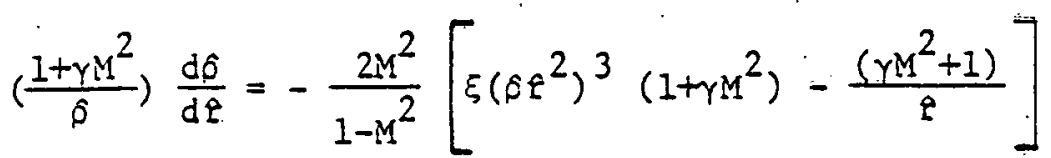


Finally, the relationship describing $\rho(r)$ is obtained by solving the above equation for $\frac{d \hat{~}}{d \hat{r}}$.

$$
\frac{d \hat{\phi}}{d \hat{r}}=-\frac{2 M^{2} \hat{\rho}}{1-M^{2}}\left[\xi\left(\hat{\rho} \hat{r}^{2}\right)^{3}-\frac{1}{\hat{L}}\right]
$$

and again:

$$
\frac{d M}{d P}=\frac{M}{1-M^{2}}\left[\xi\left(\rho P^{2}\right)^{3} M^{2}\left(1+M^{2}\right)-\frac{2+(\gamma-1) M^{2}}{P}\right]
$$

The boundary condition on the above system of equations (cf. Foster and Milora)* are as follows:

$$
\begin{aligned}
& \beta(p=1)=1 \\
& M(p=\infty)=\sqrt{5 / \gamma}
\end{aligned}
$$

This system of equations may be solved in the following manner. Since the second boundary condition, shown above, is somewhat inappropriate, two possibilities exist for the solution of equs (6) and (7). These are:

(i) Shoot a solution by assuming a value for $M(r=1)$; or

(ii) Solve the above system of equations for $M(t=1)$ but as this is a somewhat complicated procedure, it is described more or less fully in Appendix II.

In any case, equations (6) and (7) may be solved simultaneously to find $\rho(r)$ (and $M(r)$ ) and finally, $\rho(\xi)$ may be integrated to yield a value for $f(\xi)$ and thus, $\xi^{-1 / 3} f(\xi)^{-1}$. This must be done numerically, since equations (6) and (7) are sufficiently complicated that, were they uncoupled, it is doubtful that they could be solved in closed form, but they can be solved.

In the computer program that follows, Haming's fifth order generai predictor-corrector has been used with a fourth order Runge-Kutta-Gill starter to solve the CDEs. The program then solves for $\xi^{-1 / 3} f(\xi)^{-1}$ and uses this quantity to determine pellet velocity requirements. It was this program that 
generated results for figures 1 and 2 (solutions of equations (6) and (7) for $\xi=1000$ and $\xi=1.53 \times 10^{4}$ ) and figure 3 , velocity requirement as a function of pellet penetration. Pressure requirement figures were generated by a separate computer program, not supplied here. 
I SN 0002

I SN 0003

I SN 0004

I SN 0005

I SN 0006

ISN 0007

I SN 0008

I SN 0009

I SN 0010

I SN 0011

I SN 0012

ISN 0013

ISN 0014

I SN 0015

ISN 0016 .

ISN 0017

ISN 0018

I. SN 0019

I SN 0020

ISN 0021

1 Sis 0022

ISN 0023

I S.N OC. 4

I SN 0025

ISN 0026

I Siv 0027

I SN 0028

i 5110029

1 SiN 0030

ISiN 0031

i Sil 0032

I SN 0033

I SN 003:

I Sil 00.35

I Siv 2036

i S.Y 0037

I SN 0038

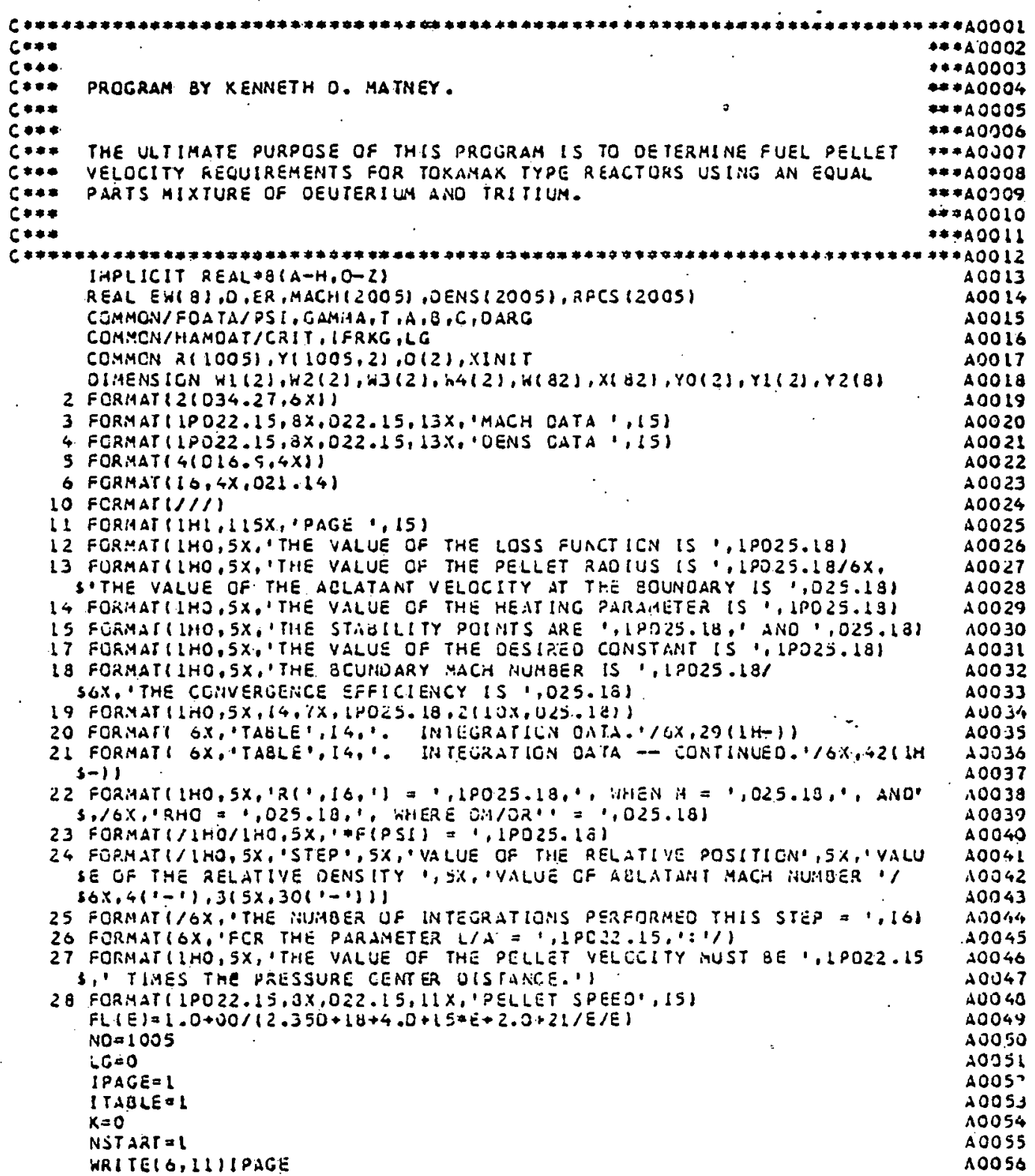


$15 N 0039$

ISN 0040

ISN 004 I

I SN 0042

I SN 0043

I SN 0044

ISN 0045

I SN 0046

I SN 0047

ISN 0048

I SN 0049

ISN 0050

ISN 0051

1 SN 0052

ISN 0053

I SN 0054

I SN 0055

ISN 0050

ISN 0057

I SN 0058

I SN 0059

I SN 0060

$15 N 0061$

I SN 0062

I SN 0063

I SN 0064

I SIV 0005

I SN 0066

ISN 0067

I SY 0063

I SN 0069

I SN 0070

$15 N 0071$

I Siv 0073

ISN.0074

isin 9075

IS. 0076

I SN 0079

I SN 0079

I SN 0080

I SN 2001

I SY 0082

ISN 0083

I SN .0084

ISN 0085

I SN 0086
I PAGE- ( PAGE + )

REAO $(5,6) \mathrm{N}$

DO $100 \mathrm{j}=1, N, l$

READ $(5,5) \times(j), X(J)$

$x(J+N)=(1.0+00+x(j)) / 2.0+00$

$x(J)=(1.0+00-x(J)) / 2.0 \times 00$

$H(J) \quad=H(J) / 2.0+00$

$H(J+N)=W(J)$

100 CCNTINUE

NSAYE $N+N$

$N=N S A V E$

READI 5,5$) E M A X, D N, V O, R P$

$E=1.60218920-19$

$X M=(2.014102220+00+3.016049720+001 * 1.6605710-27$

$P l=3.1415926535897930+00$

$G A M H A=1.40+00$

$P S I=0.0+00$

$00105 \mathrm{~J}=1, \mathrm{~N}, 1$

$P S l=P S(+W(J) * F L(E M A X=X(J))$

105 CCNT INUE

WR:?E $(6,12)$ IP S

Wt TE(6,13)RP, VO

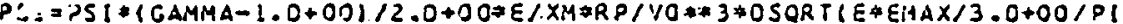

$5 / 16605710-27 / 548.5790-06) \neq 0 N$

$T=M A X=2.0+00 / 3.0+00$

REAO $(5,2)$ IS LAVE, 2 SAVE

$S=-1.0+00 / 3.0+00$

CRIT $=0$ SORT (S.OO OO/GA.MMA)

READ $(5,6$ INSAV,HSAV

REAO (5, O) NTABLE

110 CONTINUE

REAO (5, 2, ENOA999) XMACH, OEL TA

C** THE PURPOSE OF THIS, AN CGVICUS AOOITION TO THE MAIN PROGRAM, IS

KCUCD THE CPU BUT IAAINTA IN THE INTECRITY IN

CH** SINCE THE FCLLOWING SECTICN CNLY COMPUTES THE VALUE CF THE

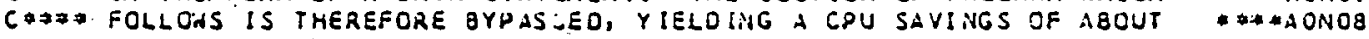

$C \neq *=902$.

* $A 2 N O Z$

- $\rightarrow 20 N 10$

**AON11

AON 12

DATA CONST/1.09776345588615600/

IFIJPAGE.GT.OIGQ TO 337

ROSAV $1.0+00$

RHOSAV $=1-D+00$

NINC $=5.0-3 / H S A V+5.0-3$

IF IMINC.LT. IIN.INC = I

NEWT $A B=0$

INIT ILAI

H=HSAV

$R O=R O S A V$

$Y O(1)=X M A C H$

YO( 2$)=: Z H O S A V$

FPS $\rfloor=0.0+00$

$N C=2$

$A L=A$ ISAYE 


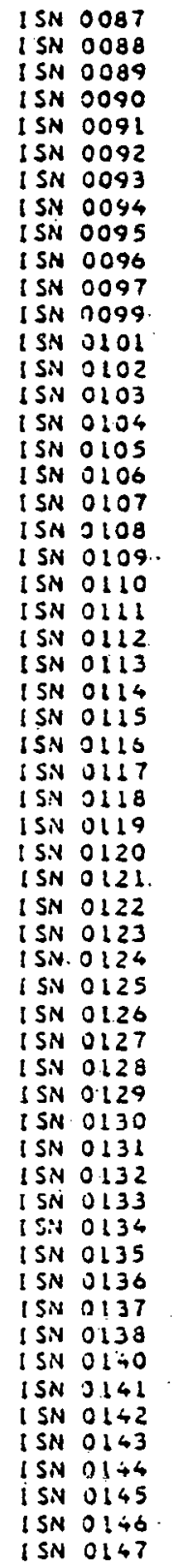

$A 2=A 2 S A V E$

IFRKGA-

HRITE $(6,14) P S !$

WRLTEIOIISI MISAVE, AZSAVE

WRITE 6.19 IINITIL,ROSAV, RHCSAV, XMACH

HRITE $(6.23)$ FPSI

WRITE $(0,11)$ I PAGE

IPAGE $=$ IPAGE+I

MSTORE $=0$

IF (NEWTAB.EQ.O) HRITEIO,2O) IT IBLE

IFINEHTAU.EO.1)WRITE 6,2 I) ITABLE

WAITE $(0,24)$

NEHT $A B=1$

LINES $=0$

120 CONTINUE

$N=1003$

CALL HAMMIN IRO,YO,NC,N,H,AL,A2,ER,R,Y, I,YZ,YL,HL,H 2,H3, K4, O,EH,NOI NSTORE $\cong N S T C R E+1000$

$N=1001$

$00200 \mathrm{~J}=3, \mathrm{~N}, 2$

FPSI $=F P S I+(Y(J-2,2)+4.0+00 * Y(J-1,2)+Y(J) Z J) * C A B S(H) / 3.0+00$

200 CONT INUE

OO $300 \mathrm{~J}=N S T A R T, N, N I N C$

WRITE(6,19)J,R(J),Y(J,2),Y(J,L)

$x=x+1$

$R P O S(K)=R(J)$

MACH(K)=Y J, 1$\}$

CENS $(K)=Y\{J, 2\}$

LINES $=$ L INE $S+1$

IF IL INES-20) $300,250,250$

250 CONTINUE

$(F(J+125-N) 275,300,3.30$

275 CONTINUE

WRITE(6,1) IIPAGE

IPACE=IPACE+I

LRITE $(6,2\rfloor)$ TTABLE

WR ITE $(\dot{6}, 24)$

LINES $=0$

300 COMTINUE

$\mathrm{N}=\mathrm{N}-\mathrm{I}$

IFRKG $=$ ! FRKG + 1

DO $320 \mathrm{~J}=1.4,1$

$00310 L=1, N C, 1$

$Y(J, L)=Y(J+N, L)$

310 CONTINUE

$\sin =R(j+i)$

320 CCNT IHUE

NSTART $=N 1 N C+1$

IFINSTOES. GE.NSAVILO TO 330

GO TO 120

330 CCNTIYUE

UR ITE(G, LI) I PAGE

IPACE = I PAGE+I

YNEF $F=Y(N, 11 / C R I T=1.02$

WRI TE $(6,18) \times$ Y ICH, YNEFF

HR ITE 16,25 HNSTORE

OMOR $=F(1, R, Y, M)$

10106

20107

A0108

A0109

$A 0110$

A 0111

A0112

$\triangle O \perp 13$

10114

40115

AOL16

A0117

40118

A.0 119

40120

10121

10122

AD 123

AO 124

A 0125

AO $\$ 26$

A0 121

40128

10129

40130

40131

$\wedge 0132$

40133

20134

40135

A 0136

10137

AOL138

AO 139

AO 140

40141

40142

AO 643

40144

AO 145

AO 146

40147

AO 148

$\triangle 0149$

10150

$10\lfloor 51$

AO 152

AD 153

AOL 54

A0.15.5

10156

10157

AO 158

A0159 
ISN 0148 I SN 0149

I SN 0150 ISN O151

ISN 0152

I SN 0153

ISN 0154

ISN 0156

I SN 0157

ISN 0158

ISN 0159

ISN $0160^{\circ}$

ISN 0101

I SN 0162

ISN 0163

ISN 0164

I.SN OIA5

ISN 0166

ISN 0167

1 SN 0108

ISN 0169

ISN 0170

ISN 0171

ISN 2172

ISN OI73

ISN 0174

ISN $0 ! 75$

I SN 0176

ISN 0$\rfloor 77$

ISN $0 \$ 79$

I SN 0179

ISN O 180

I. SN 0131

ISN 0192

ISIN 0183

1 SN 0184

I SN 0.85

I SN 0176

I SN 0107

ISN 0189

1 Sid 0190

[SN 019$]$

1 SiN 0192

I SN 0693

I SN 0194

ISN OI95

[ SiN.0197

ISN 0198

I SN O199

I SN 0200

ISN 0201 .

I SN. 0202

I SN 0203

ISN 0204
HR ITE 16,22 JNSTORE, R (N), Y (N, I), Y (N, 2),DMOR

VALUE $=3.00 / 4.00 /((2.00+($ GAMH A- 1.00$) * Y(N, 1) * 2) / P S[/ Y(N, 1) * 2 /(1.00$ $S+G A M M A \cdot Y(N, 1) \cdot 2)) \cdot S$

FPS $1=F P S I+R(N) *(4.00 * S) * V A L U E$

CONST $=P S I * S / F P S I$

WRITE(6.23)FPSI

WRITEI6.17ICONST

IFIYNEFF.LT.90.1GO TO 345

$00333 \quad P=1, X, 1$

PUNCH 3, RPCS $(19)$, MACH $(P)$, IP

333 CONTINUE

00. $336 \quad|P=1, K$,

PUNCH $4,2 P O S(I P)$, OENS $(18), 18$

336. CONT INUE

337 CONTIUUE

WRITE ( 6.11$) I P A G E$

IPAGE $=1 P A G E+1$

$X I N I T=0.000$

ICOUNT=6

$X, 40=2.01410222 .00 * 1.6605710-27$

$X M E=5 \% 8.5790-6 * 1.6605710-27$

$X M H=1.0086652200 * 1.6605710-27$

$A=C C N S T /(P I * X M E) \approx(1,-00 / 6.00) \neq(X M 0 / 2.05902) *(4.00 / 9.00) * 0 S G R T(E) *$ $3(2.35019) *(2.00 / 3.20) *(4.00 * P ! / 3.00) *(5.00 / 9.00) *(1.500 / 1.600) *$

$s(7.00 / 6.00)=(3.00 / X M H)=(1.00 / 3.00) / T=11.00 / 6.0 \mathrm{C})$ $8=9.00 / 3.7603$

$C=-4.0960213 .80700$

DARG $=2.320801 / 1.057500$

FYOL $=4 . D O * P[/ 3.00 * R P \# R P \approx R P * 2.05902 / O N X Y O$

338 CONTINUE

WRITE(6.26) XINIT

$\mathrm{H}=1, \mathrm{O}-2$

$V I=C(T, H) /(X M / X A H) *(1.00 / 3.001 / F V O L * *(5.00 / 9.001 / 0 A * *(2.00 / 9.00)$

MRITE16.27IVI

$H=1 \cdot 0-3$

$V 2=C(T, H) /(X M / X, 4 H) \neq(1.00 / 3 . C O) / F V O L=(5.00 / 9.00) / 0 N=(2.00 / 9.00)$

ํ.

XPENET $=2.00-X I N I T$

I COUNT = ICGUNT + 1

PUNCH 28,XPENET, V2,ICOLNT

$X I N I T=1.00-X P$ ENET $+2.0-1 * 1.0-2$

IF(MCDIICCUNT,6) E E0.01GO TO.339

WRITE $(6,10)$

CO 10340

339 CONTINUE

HRITE(G, 11)IPAGE

I PAGE IPACE I I

340 CONTINUE

(FIVZ.GT.1.02) LO TO 338

345 CONTINUE

WR ITE $O O, 11$ I PACE

IPACE I PACE+!

ITABLE = ITABLE+I

CO TO 110

999 CENTINUE

STOP

END
A0160

A0161

40162

0163

AOI64

A0165

$A 0166$

40167

40168

40169

A01 70

A0171

40172

40173

A0176

40175

40176

A0177

$40\lfloor 78$

10179

AO 180

40181

$\triangle 0182$

AO 183

40184

A 0185

40186

A 1197

AO 188

40189

A0190

40191

A 192

40193

20194

A.0195

AD 19B

40197

A0 198

40 199

40200

10201

40202

$\triangle 0203$

10204

$\triangle 0205$

40206

$\$ 0207$

40208

$\triangle 0209$

40210

$\triangle 0211$

A0212

$A 0213$

A021\%

2021 ;

A0 216 
I SN 0002

I SiN 0003

I SN 0004

I SN 0005

I SN 0006

I SN 0007

I SN 0008

I SN 0009

ISN 0011

I SN 0012

I SN 0013

i SiN 0014

$1 \sin 00: 5$

ISN 0016

I SN $00 ! 7$

I SN 0013

I Sin 0019

I SN 0020

I SN 0021

I SN 0022

I. Si 0023

I SN 0024

I SH 0025

I SN 0026

I SN 0027

I SN 0028

I SN 0029

I SN 0030

ISN 0031

I SN 0032

I SN 0034

ISN 0035

ISN 0036

I SN 0037

I SN 0038

I SN 0039

I SN 0040

ISN 0041

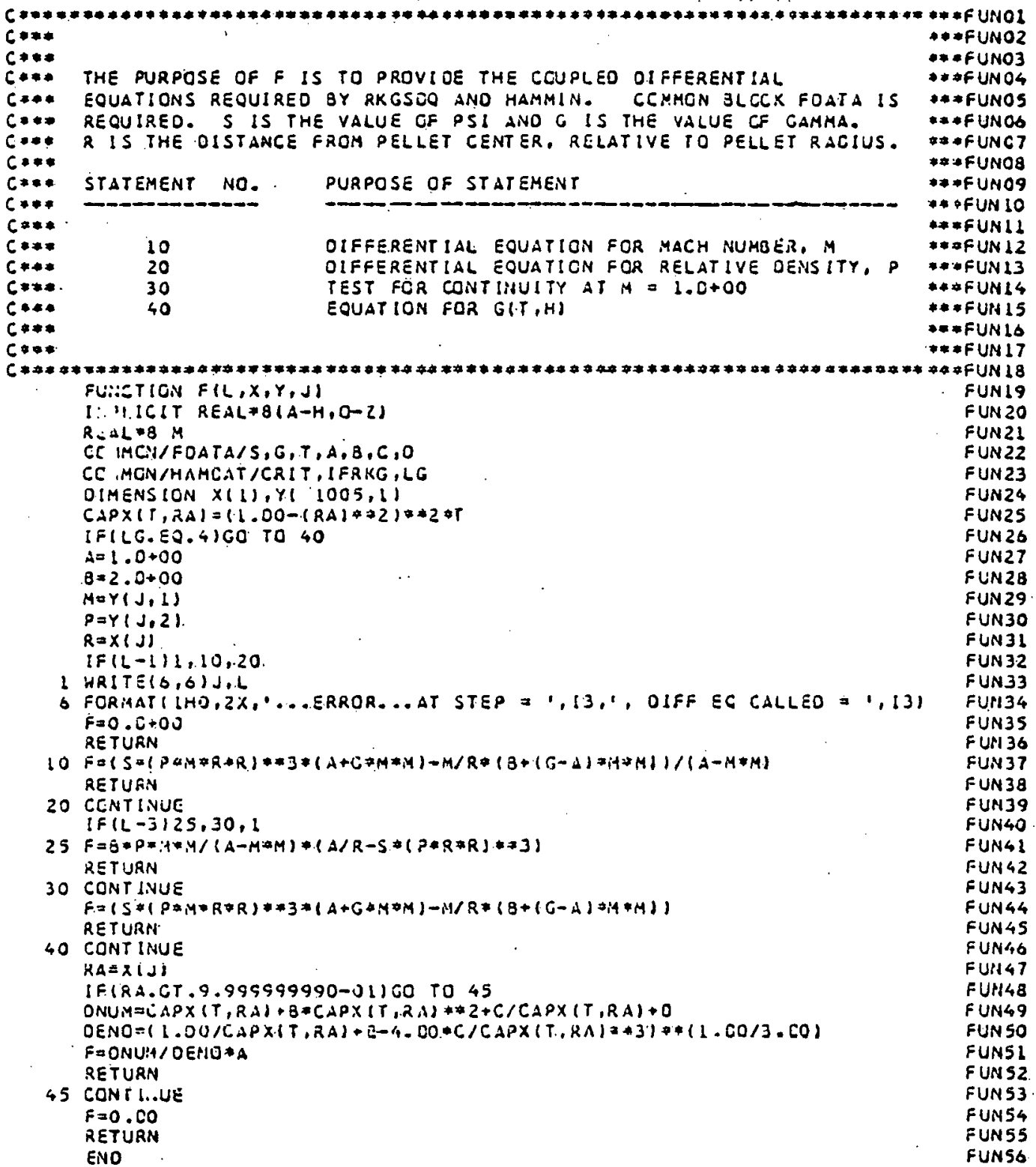


OS/360 FORTRAN H

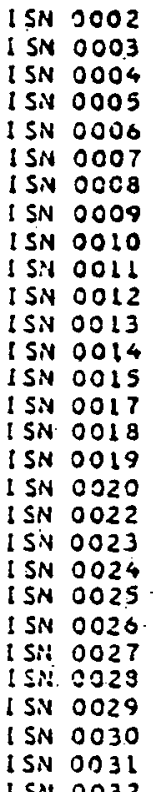

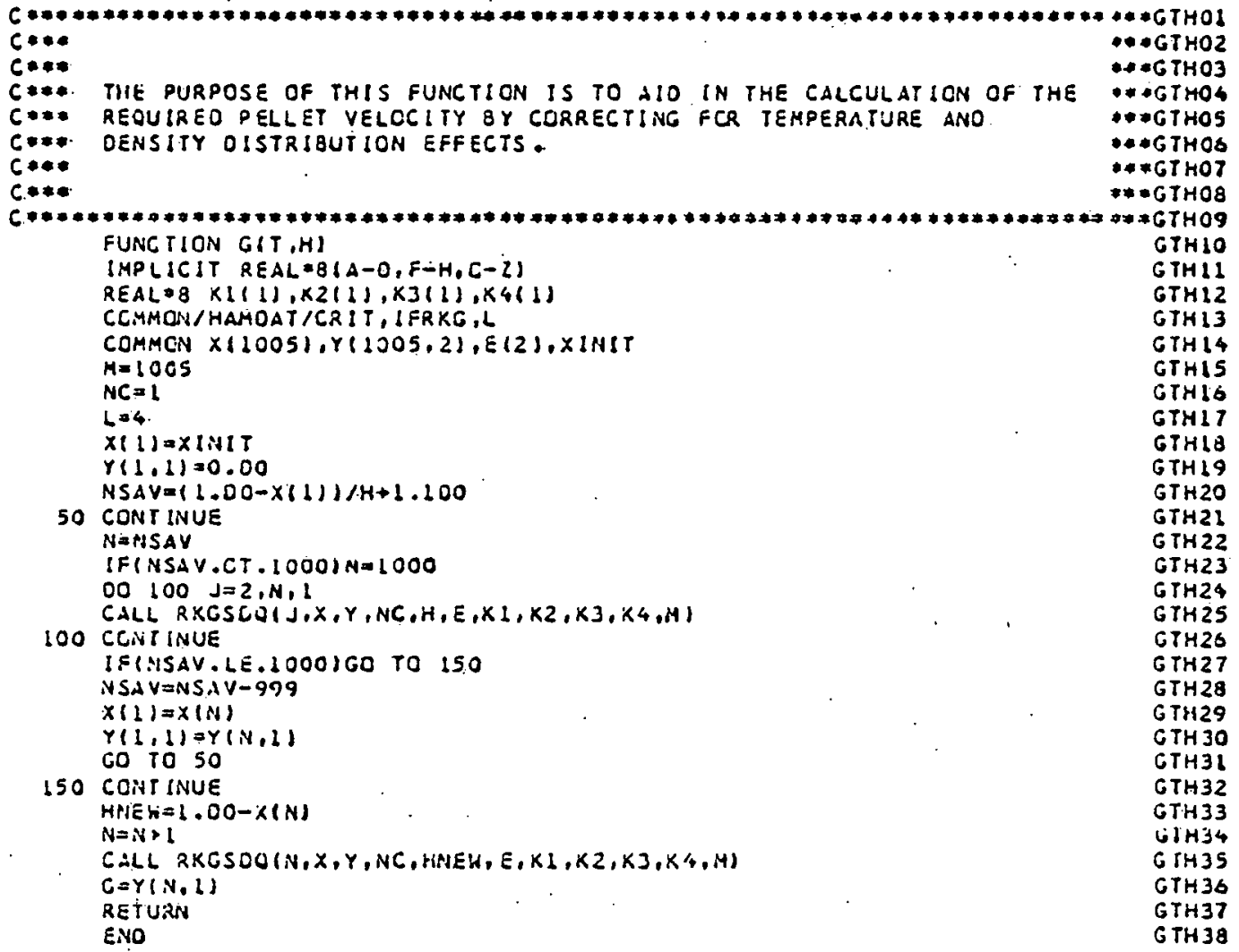


I Si 0002

[ SN :0003

ISN 0004 I SN 0005

I SN 0006 I SN 0007

I SN 0008

I SiN 0009

ISN. 0010

ISN. 0011

1. SiN 0012

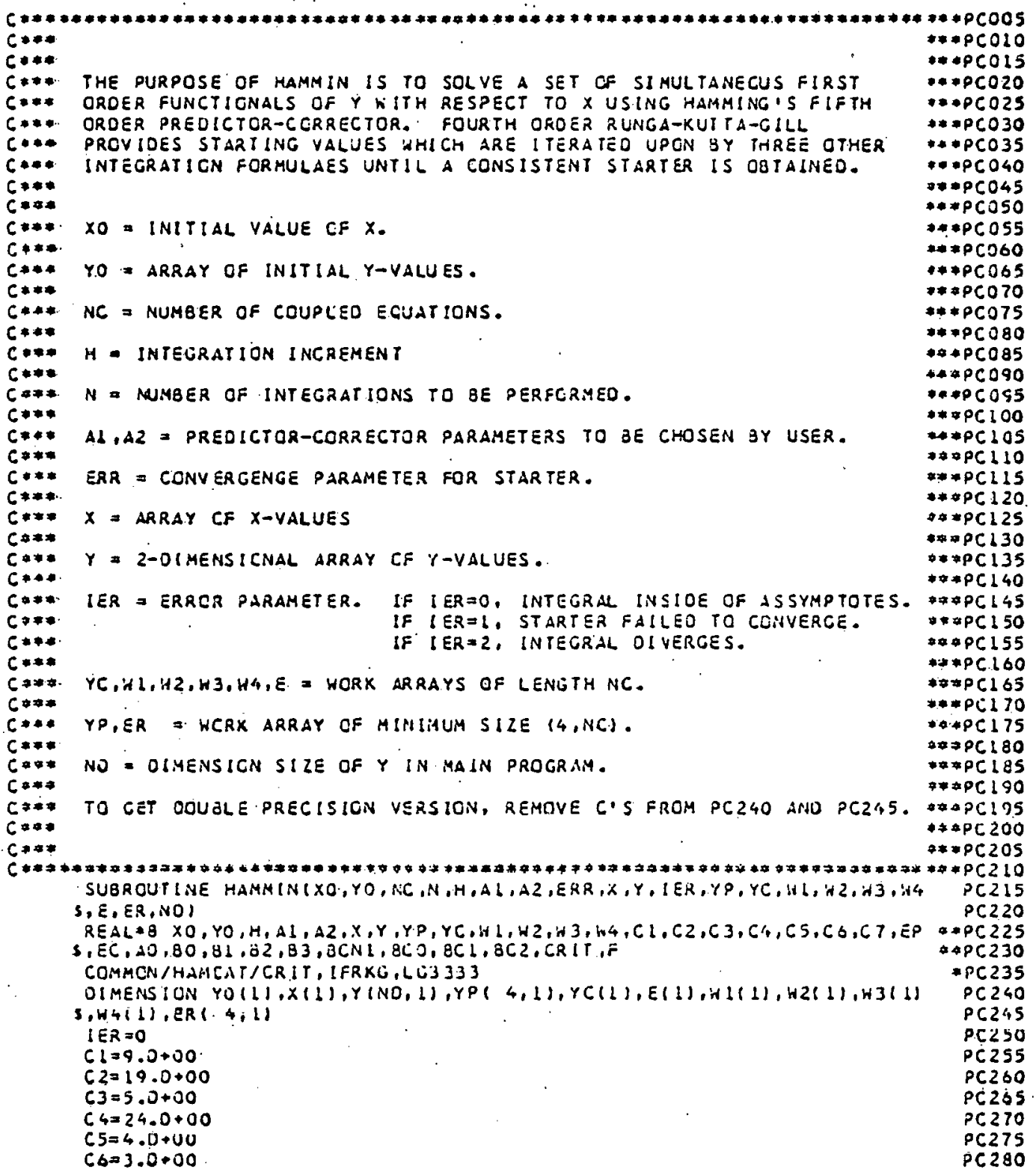




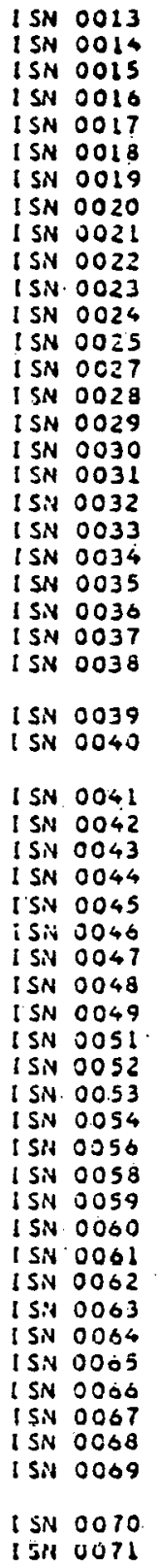

$C 7=8.0+00$

$E P=(2.510+02-C 2 * A 1-C 7 * A 2) / 6.0+00$

$E C=1-C 2+11.0+00 * A 1-C 7 * A 21 / 6.0+00$

$\Delta O=1.0+00-A 1-A 2$

$B O=(55.0+0 O+C) * A 1+C 7=A 2) / C 4$

$B 1=1-59.0+00 \cdot C 2 * A 1+32.0+00 * A 2) / C 4$

$82=(37.0+00-C 3 * A 1+C 7+A 2) / C 4$

$B 3=(A 1-C 1) / C 4$

$B C N \mid=\{C l-A|l| C$.

$B C O=1 C 2+13-0+00 * A 1+C 7 * A 21 / C 4$

$B C 1=(-C 3+13 . D+00 * A 1+32.0+00+A 2) / C 4$

$B C 2=(1.0+00-A 1+C 7 * 12) / C 4$

IFI IFRKG.GE.OIGO TO 155

$x \backslash 1]=\times 0$

CO $100 \quad L=1, N C, 1$

$Y(1.16)=Y O(L)$

100 CGNTINUE

00 i15 $J=2,4,1$

CALG RXGSOOIJ,X,Y,NC,H,E,H L, H2,H3,H4,NOS

115 CORTINUE

JC $\varepsilon C X=0$

120 Cr.arinue

JC: $\leqslant C X=J C H E C X+1$

DO $i 30 \mathrm{~L}=1, \mathrm{HC}, \mathrm{L}$

$Y P(Z, L)=Y(L, L)+H *(C) * F(L, X, Y, L)+C Z * F(L, X, Y, Z)-C\} * F(L, X, Y, 3)+F(L$, $S X, Y, 4) 1 / C 4$

$Y P(3, L)=Y(1, L)+H *(E(L, X, Y, L)+C 5 * F(L, X, Y, Z)+F(L, X, Y, 3)) / C b$

$Y P(4, L)=Y(1, L)+H *(F(L, X, Y, L)+C G *(F(L, X, Y, Z)+F(L, X, Y, 3))+F(L, X, Y$ $3,4,1 / 1,7 * C_{6}$

DO $125 \mathrm{~J}=2,4,1$

ER(J,L) $=(Y(J, L)-Y P(J, L)) / Y(J, L)$

ER (J,L)=ASS (ER (J.L))

125 continue

130 CONTINUE

ITES $T=0$

$00 \quad 140 \quad$ LEI,NC.1

$00.135 \mathrm{~J}=2,4, \mathrm{l}$

IF (ERIJ.L) .GT.ERR ITTEST=

$Y(J, L)=Y P(J, L)$

135 CCNT LIYUE

$140 \cdot$ CONTINUE

IF ( JCHECK. GE. 50J)CO. TO 145

IFIITEST.EO.LIGU TO 120

$14500150 \quad L=1, N C, 1$

$Y P(L, L)=0.0+00$

$Y C(L)=0.0+C 0$

150 CONTINUE

is 5 . CONI INUE

$00300 \mathrm{~J}=4, \mathrm{~N}, \mathrm{I}$

$x(j+1)=x(j)+H$

$00 \quad 175 \quad L=1, N C, L$

YP $(2, L)=Y P(1, L)$

17: CONTINUE

OO $200 \quad L=1, N C, 1$

$Y P(I, L)=A O=Y(J, L)+A L * Y(J-1, L)+A Z * Y(J-2, L)+H \geqslant(Q O * F(L, X, Y, J)+\forall L * F(L$ $3 X, Y, J-1 J+82 * F(L, X, Y, J-2)+B\} * F(L, X, Y, J-3 J)$

200 CCNTINUE DO 225 L 1 , NC. 1
$P C 285$

$P C 290$

$P C 295$

$P C 300$

$P C 305$

PC310

PC 315

PC 320

PC 325

PC330

PC335

PC340

PC 345

PC 350

PC355

PC360.

PC 365

PC 370

PC375

PC 380

PC385

PC 390

PC355

PC400

PC 405

PC4 40

PC415

PC420

PC4 25

PC430

PC435

PC440

$P C 445$

Pr. 450

PC455

PC400

PC 465

$P 6470$

PC475

PC480

PC485

$P C 430$

PC495

PC500

PC505

PCSIO

PC515

PCS 20

PCS25

PC 330

PC535

PC540

PC 5:.5

PC550

PC5SS

$P C 560$

PC565

PC570 
I SN 0072

ISN 0073

I SN 0074

I SN 0075

ISN 0076

ISN 0077

I SN 0078

I SN 0079

ISN 0080

I SN 0031

ISN 0032

I SN 00.83

I SN 0084

I SN 0085

I SN 0086
$Y(J+1, L)=Y P(1, L)-(E P /(E P-E C)) *(Y P(2, L)-Y(L)) \quad P C 57 S$

CONTINUE

OO $250 L=1, N C, L \quad$ PCSBS.

$Y C(L)=A O * Y(J, L)+A L * Y(J-1, L)+A Z * Y(J-2, L)+H *(B C N L * F(L, X, Y, J+L)+B C O * F \quad P C 590$

$B(L, X, Y, J)+B C L * F(L, X, Y, J-L)+B C Z * F(L, X, Y, J-Z)) \quad$ PC595

250 CONTINUE $\quad$ PC600

00275 L=L,NC, $1 \quad$ PCO05

$Y(J+1, L)=Y C(L)-1 E C /(E P-E C)) *(Y P(L, L)-Y C(L))$

$\begin{array}{ll}\text { IF(J-N) } 285,300,400 & \text { PC620 }\end{array}$

285 CONTINUE

300 CONT INUE

PC635

RETURN

END 
OS/360 FORTRAN H

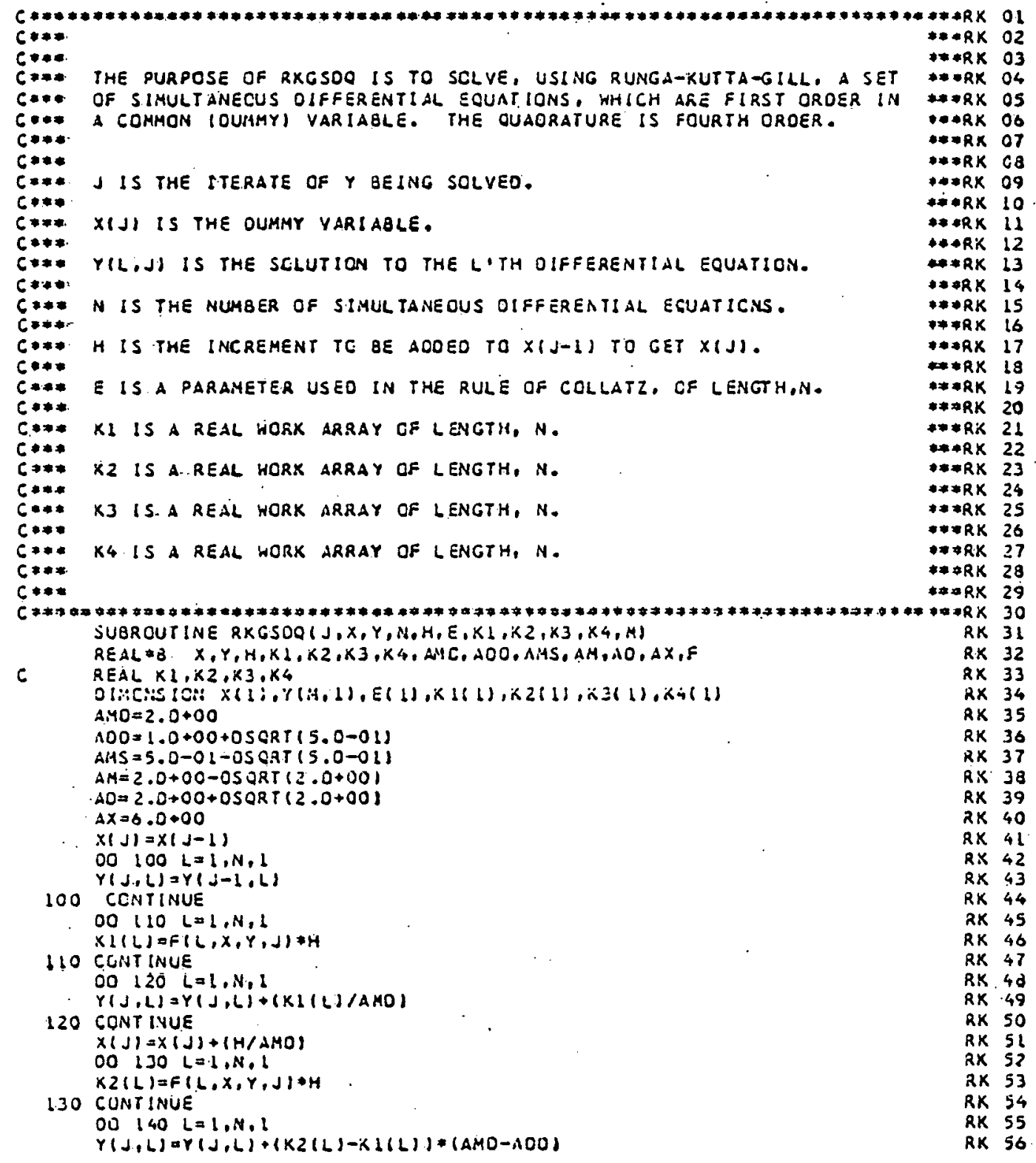


I SN 0027

I SN 0028

ISN 0029

I SN 0030

ISN 0031

ISN 0032

I SN. 0033

I SN 0034

I SN 0035

ISN 0036

ISN 0031

I SN 0038

ISN 0039

I SN 0040

ISN 0041

I SN 0042
140 CONT INUE .

$00150 \quad L=1, M, L$.

$X 3(L)=F\left(L, X_{0}, Y_{0} J\right) * H$

150 CONTINUE

DO $1.60 \quad L=1, N, L$

$Y(J, L)=Y(J, L)+A M S * K L(L)-K 2(L)+A D O+K 3(L)$

160 CONTINUE

$x(J)=x(J-1)+H$

$00170 \quad L=1, N, L$

$K 4(L)=F\left(L, X_{,}, Y, J\right) \neq H$

170 CONTINUE

$00180 \quad L=1, N, L$

$Y(J, L)=Y(J-1, L)+\{K L(L)+A .4 * K Z(L)+A 0 * K 3(L)+K 4(L)) / A X$

C $\quad E(L)=(K 2(L)-K 3(L)) /(K 2(L)-K L(L))$

$E(L)=A D S(E(L))$

180. CONTINUE

RETURY

ENO
RK 57

RX 58

RK 59

$2 \times 60$

RK 61

RK 62

RK. 63

RK 64

RK 65

$R \times$ Sb

RK 67

RK 68

RK 69

RK 70

RK 71

AK 72

RX 73

RK 74 
Appendix II. Determination of Pellet-Surface Mach Number.

Although the appropriate value for the pellet-surface Mach number, $\left.M(\hat{r})\right|_{\hat{r}=1}=M_{0}$, can be deterwined, in principle, by a trial-and-error approach, the computational effort involved may turn out to be very substantial and perhaps prohibitively expensive. The degree and severity of this concomitant practical difficulty tends to increase with 1ncreasing values of the heating parameter, $\xi$. While such a trial-and-error approach 1s perhaps viable for the heating-parameter values considered by Milora and Foster $(\xi=10,100,1000)$, the corresponding heating parameter for CTHR $(\xi=15300)$ is much larger and a more sophisticated semi-analytical method merits serious consideration.

The given system of differential equations to be solved is comprised of equations (6) and (7), i. e.,.

$\frac{d M}{d q}=\frac{M}{1-M^{2}}\left(\xi M^{2}\left(\rho \rho^{2}\right)^{3}\left(1+Y M^{2}\right)-\frac{2+(Y-1) M^{2}}{\hat{L}}\right)$

$\frac{\mathrm{d} \dot{\mathrm{O}}}{\mathrm{d} \hat{\mathrm{r}}}=\frac{2 \mathrm{M}^{2} \delta}{1-\mathrm{M}^{2}}\left(\frac{\mathrm{l}}{\hat{\hat{\mathrm{T}}}}-\xi\left(\hat{\rho} \hat{\mathrm{L}}^{2}\right)^{3}\right)$

The relevant boundary conditions, expressed by equations ( $8 a$ ) and ( $8 b$ ), are

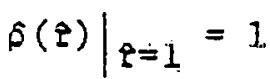

and

$M_{\infty}=\underset{r \rightarrow \infty}{\lim } M(\beta)=\sqrt{5 / \gamma}$

However, the companion condition

$\left.M(\varepsilon)\right|_{E=1}=M_{0}$

is not given in terms of a known boundary value. Thus, immediate numerical integration is precluded, save for a trlal-and-error approach in which one tries to guess the correct value of $\mathrm{M}_{0}$. 
Several other conditions must be satisfied on physical grounds. First of a11,

$\frac{d M}{d \underline{l}}>0$

which Implies, as noted by Milora and Foster, that the bracket expression on the right-hand side of equation (6) must be positive at subsonic velocities, where $M<1$, and negative at supersonic velocities, for which $M>1$; at the sound barrier, characterized by the Mach-number value $k=M_{1}=1$, the expression must vanish to preclude an unacceptable singularity. Similarly, one must expect that

$\frac{d \delta}{d \hat{L}}<0$

to avoid a condition which would trigger recoalescence; correspondingly, the bracket term on the right-hand side of equation ( 7 ) must be negative when $M<1$, zero when $M=M_{1}=1$, and positive when $M 1$.

The last sound-barrier condition, which requires that

$\left(\frac{1}{\hat{\mathrm{P}}}-\xi\left(\hat{\rho} \hat{\mathrm{L}}^{2}\right)^{3}\right)_{M=1}=0$

to prevent a physically unacceptable singularity, provides the motive for introducing the substitution

$$
\delta=\pi \xi^{-1 / 3} e^{-7 / 3}
$$

where $n=n(p)$ represents a new dependent variable. From equation (13). it follows by rearrangement that

$\varepsilon\left(p e^{2}\right)^{3}=\frac{n^{3}}{\dot{L}}$

Consequently, the sound-barrier condition reflected in $M=M_{T_{2}}=1$, equation (12), can be reformulated as

$n_{1}=\left.n(Y(M))\right|_{M=1}=1$ 
where $\hat{z}=\hat{F}(M)$ is the inverse function of $M=M(\hat{L})$; thus the soundbarrier value of the new varlable $\eta$ is known to be untty.

Pursuant to the substitution given in eqution (13), the differential equations (6) and ( 7$)$ can be rewritten in terms of the variables $\hat{r}, M$, and $\eta$; one finds easily:

$\frac{d \eta}{d \hat{r}}=\left(\frac{7-M^{2}\left(1+6 \eta^{3}\right)}{3\left(1-M^{2}\right)}\right) \frac{\eta}{\hat{r}} \equiv \frac{V}{\left(1-M^{2}\right) \hat{r}}$

$\frac{d M}{d \hat{r}}=-\left(\frac{2-M^{2}\left[\left(1+n^{3}\right)-Y\left(1-M^{2} n^{3}\right)\right]}{1-M^{2}}\right) \frac{M}{\hat{L}} \equiv-\frac{U}{\left(1-M^{2}\right) \hat{r}}$

The two polynomials $U=(M, n)$ and $V=V(M, n)$, introduced for convenience in notation, are defined uniquely by virtue of the identities in equations (17) and (16), respectively. By introducing the further simple transformation

$s=109$

one obtains an autonomous system: of differential equations, namely:

$\frac{d n}{d s}=\frac{\left[7-M^{2}\left(1+6 n^{3}\right)\right] n}{3\left(1-M^{2}\right)} \equiv \frac{\dddot{V}}{1-M^{2}}$

$\frac{d M}{d s}=-\frac{\left\{2-M^{2}\left[\left(1+n^{3}\right)-Y\left(1-M^{2} n^{3}\right)\right]\right\} M}{1-M^{2}} \equiv-\frac{U}{1-M^{2}}$

Then, elimination of the parametric variable $s$ from these equations yields $\frac{d M}{d n}=-\frac{3 M\left\{2-M^{2}\left[\left(1+n^{3}\right)-y\left(1-M^{2} n^{3}\right)\right]\right\}}{n\left[7-M^{2}\left(1+6 n^{3}\right)\right]} \equiv-\frac{U}{V}$

By way of their definition, the polynomials $U \doteq U(M, n)$ and $V=V(M, n)$ represent the numerator and denominator of the given fraction, respectively.

This formulation of the problen at hand allows the application of standard methods germane to the theory of nonlinear differential equations, particularly geometric considerations developed originally by Poincaré and 
Liapounov (see, for example, Chapter 9 in "Elementary Differential Equations and Boundary Value Problems" by W. E. Boyce and R. C. DiPrima, John Wiley \& Sons, 3rd ediliva, 1977).

The regime of physical interest is contained in the positive real domain of the variables, that is, where $M>0$ and $n>0$; this domain is bounded by the two obvious solutions $M=0$ when $n>0$ and $n=0$ when $M>0$, with the origin $M=0$ and $n=0$ belng a critical point (readily recognized on geometric grounds to be a saddle point). Within the positive real domain, there are two critical points at which the numerator and denominator on the right-hand side of equation (21) vanish simultaneously. Solution of the appropriate simultaneous algebraic equations yields readily the criticalpoint coordinate values.

One of these critical points is given by

$$
M_{\infty}=\sqrt{5 / \gamma} \text { and } \eta_{\infty}=\sqrt[3]{(7 \gamma-5) / 30}
$$

Comparison with equation ( $8 b)$ reveals that this critical point matches the asymptotic limit as $\lim \hat{\mathrm{r}} \rightarrow \infty$. It is easy to show that the condition

$$
n_{\infty}=\lim _{\tau \rightarrow \infty} \eta(\hat{r})=\sqrt[3]{(7 \gamma-5) / 30}
$$

is, indeed, the appropriate condition for the asymptotically stable solution as suggested by Milora and Foster. Thus, this critical point must be the asymptotic limit of the desired solution; the asymptotic expression

$\sigma(\mathrm{e})-\eta_{\infty} \xi^{-1 / 3} \hat{\mathrm{r}}^{-7 / 3}$

follows by substitution into equation (13). This guarantees the necessary convergence of the improper integral defining $f(\xi)=\delta_{1}^{\infty} \delta(\hat{\xi})$ de. For the specific case at hand in this report, $\gamma=7 / 5$, then $M_{\infty}=1.88982$ and $\eta_{\infty}=0.54288$.

Assuming $M-M_{\infty}$, one obtains readily $\delta-C p^{-7 / 3}$ by separation of variablas in equation (2). Subsequent substitution into equation ( 7 ) yields $c-n_{\infty} \xi^{-1 / s}$ in agreement with equation (24). 
The other critical point is found to be at

$$
M_{1}=1 \text { and } \quad n_{1}=1
$$

Comparison with equation (15) shows that this critical point represents the sound-barrier condition. Therefore, it must be contained in the solution being sought.

To exploit this most essential feature, the specific character of this critical point must be explored in detail. In a sufficiently small vicinity of the critical point, with $M^{*} 1+\mu$ and $\eta \approx 1+\varepsilon$, the linear autonomous system of differential equations

$$
\begin{gathered}
\frac{d \varepsilon}{d \tau}=18 \varepsilon+14 \mu \\
\frac{d \mu}{d \tau}=-9(\gamma+1) \varepsilon+6(\gamma+2) \mu
\end{gathered}
$$

where $\tau$ is a sultable paraneter, is mathematically equivalent with the differential equation (21) being investigated. The concomitant characteristic equation

$$
\lambda^{2}-6(\gamma-1)+18(\gamma-5)=0
$$

has the two distinct characteristic roots

$$
\lambda_{1}=3\left[(\gamma-1)+\sqrt{(\gamma-2)^{2}+7}\right]
$$

and

$$
\lambda_{2}=3\left[(\gamma-1)-\sqrt{(\gamma-2)^{2}+7}\right]
$$

Since the specific-heat ratio $y=(v+2) / v$, where the integer $v \geq 3$ is the number of degrees of freedom for the gas-molecule motion, is thus bounded on physical grounds by $1<y<5 / 3$, it follows that their product is negative, i.e.,

$$
\lambda_{1} \lambda_{2}=18(\gamma-5)<0
$$

so that the two characteristic roots are of the opposite sign. Consequently, the critical point of interest is diagnosed to be a saddle point.

To determine the slopes $M^{\prime}=d M / d n$ for the two solutions traversing the saddle point, let the differential equation (21) be rewritten as 


$$
V\left(\frac{d M}{d n}\right)+U=0
$$

where $U$ and $V$ represent the numerator and denominator of the fraction on the right-hand side, respectively, When evaluated at the critical point, both coefficients $U$ and $V$ vanish, of course, and equation (29) degenerates into a trivial identity. Differentiation of equation (29), while regarding $n$ as the independent variable and $M=M(n)$ as the dependent variable yields

$v \frac{d^{2} M}{d n^{2}}+\frac{\partial V}{\partial M} \cdot\left(\frac{d M}{d n}\right)^{2}+\left(\frac{\partial V}{\partial \eta}+\frac{\partial U}{\partial M}\right) \frac{d M}{d n}+\frac{\partial U}{\partial \eta}=0$

where the coefficlents can be determined easily by partial differentiation of $U=U(M, n)$ and $V=V(M, n)$. At the critical point, the coefficient $V$ is known to vanish and equation (30), becomes a quadratic equation for the saddle point slope $\mathrm{M}_{\mathrm{S}}^{2}$; after straightforward but slightly tedious mathematical manipulations to evaluate the relevant coefficients at the saddle point one finds

$$
14 M_{s}^{2}+6(\gamma+5) M_{s}^{\prime}+9(\gamma+1)=0
$$

the concomitant solutions are then

$$
M_{S 1}^{\prime}=-3\left[(y+5)-\sqrt{(y-2)^{2}+7}\right] / 14
$$

and

$$
M_{s 2}^{\prime}=-3\left[(y+5)+\sqrt{(y-2)^{2}+7}\right] / 14
$$

The product of these two roots is certainly positive, because of

$$
M_{s 1 .}^{\prime} M_{s 2}^{\prime \cdot}=9(\gamma+1)>0
$$

Ince it is obvious that $M_{S 2}^{1}>0$ based on simple inspection of the expression (326), it follows pursuant to equatton (33) that $M_{0 I}^{\prime}<0$; it is furthermore evident readily that $M_{s 1}^{\prime}>M_{S 2}^{\prime}$. Consequently,

$$
0>M_{s 1}^{\prime}>M_{s 2}^{\prime}
$$


For the spectfic case at hand in this report, $y=7 / 5$, thus $M_{s 1}^{\prime} z-0.79009$ and $M_{s 2}^{\prime}=-1.95277$; their relative magnitude is obviously in accordance with inequality (34).

With the two saddle-point slopes known, there are but two different solutions of the differential equation (21) which satisfy the already established condition that the saddle point must be part of the solution. One of these two solutions is then, of course, the physically realistic solution being sought here; which of these two possible solutions remains to be determined: To this end, a quite detailed analysis, straightforward in princlple but rather cedlous and cumbersome in practice, must be carried out, involving exploration of the isoclines $\mathrm{dM} / \mathrm{d} n=0$, for which $U=U(M, n)=0$, and $\mathrm{d} n / \mathrm{d} M=0$, for which $V=V(M, n)=0$, subsequent determination of regions In terms of the sign. the values of the polynomials $U=U(M, n)$ and $V=V(M, n)$ assume in such regions within the positive real domain for the variables $M$ and $\eta$, in combination with a distinction between subsonic and supersonic regimes, in which $\left(1-M^{2}\right)>0$ or $\left(1-M^{2}\right)<0$, respectively. By virtue of equations (21), (17), and (16) the results of such an analysis permit a solution to be characterized in terms of the sign for the deriviatives $\mathrm{dM} / \mathrm{d} n$, $\mathrm{dM} / \mathrm{d} \hat{\mathrm{s}}$, and $\mathrm{dn} / \mathrm{d} \hat{\mathrm{l}}$. Furthermora, one cran infer by differentiation of equation (13) that $\mathrm{d} \beta / \mathrm{d} \rho=[\mathrm{d} n / \mathrm{d} \rho-7 \pi / 3 q] \xi^{-1 / 3} \hat{\mathbf{r}}-7 / 3<0$ whenever $\mathrm{d} \hat{\rho} / \mathrm{d} \hat{\mathrm{r}}<0 ;$ however no conclusion may be drawn regarding the sign of the derivative $d \hat{p} / \mathrm{d} \mathbf{t}$ when $\mathrm{dn} / \mathrm{d} \hat{\mathrm{r}}>0$.

When the procedure just outlined is applied for the solution with the steeper negative slope, namely $M_{s 2}^{\prime \prime}=-3\left[(\gamma+5)+\sqrt{(\gamma-2)^{2}+7}\right] / 14$, at the saddle point, it reveals as the essential feature that $d M / d \hat{r}<0$. This is exactly contrary to the constraining condition set forth in inequality (10). Consequently, this particular choice among the two mathematically possible saddle-point solutions. must be rejected as physically unrealistic in its Eonsequences. 
By process of elimination, the alternate possibility left for practical consideration is represented by the solution with the shallower negative slope, namely $M_{S 1}^{\prime}=-3\left[(\gamma+5)-\sqrt{(\gamma-2)^{2}+7}\right] / 14$, at the saddle point. In this case, the results of the analysis employing the procedure outlined above shows that $d M^{\prime} / d \hat{p}>0, d n / d \varphi<0$, and $d \rho / d \hat{\rho}<0$ in agreement with the physical-constraint conditions stated in inequalities (10) and (11). Thus, the desired solution compatible with physical reality exists indeed and has been duly identified. The analysis indicates also that $\mathrm{dM} / \mathrm{d} n<0$, which means that the solution of interest is represented by a monotone decreasing function $M=M(n)$.

With the acquired knowledge about the saddle-point characteristics, the differential equation (2l) can be integrated numerically commencing at the saddle point at $M=M_{1}=1$ and $\eta=\eta_{1}=1$ with slope $M_{s 1}^{\prime}=-3\left[(\gamma+5)-\sqrt{(\gamma-2)^{2}+7}\right] / 14$. For the present work, two fourth-order schemes of numerical integration were chosen: the standard fourth-order Runge-Kutta method and Gill's modified method (see Chapter 25, entries 25.5.10 and 25.5.12 in "Handbook of Mathematical Functions," edited by M. Abramowitz and I. A. Stegun, 9 th printing, Dover Publications, Inc., 1972). Naturally, the numerical solutions for this report were carried out for this specific case at hand, where $\gamma=7 / 5$ as appropriate for gas with diatomic molecules. The results of the numerical solution thus obtained are graphically illustrated in Figure $A$; within the limits of numerical precision attainable in the computations, the results from both numerical-integration schemes were found to be in agreement.

The value of the acquired solution $M=M(n)$ of differential equation (21) corresponding to the pellet-surface condition where $\hat{f}=\hat{r}_{0}=1$ and $\delta=\hat{\rho}_{0}=1$, provides the desired pellet-surface condition given in equation (8a) into equation (13) yields the pellet-surtace value 


$$
\left.n(\hat{r})\right|_{\hat{r}=1}=n_{0}=\sqrt[3]{\xi}
$$

using the solution $\mathrm{M}=\mathrm{M}(n)$ one obtains then for the pellet-surface Mach number the value

$$
M_{0}=\left.M(n)\right|_{n=n_{0}}=M\left(n_{0}\right)
$$

Obviously, this process for determining the pellet-surface Mach number $M_{0}$ required that differential equation (21) be integrated numerically over the interval $1=n_{1} \leq n \leq n_{0}=\sqrt[3]{\xi}$, starting at the saddle point, where $M=M_{1}=1$ and $n=\eta_{1}=1$, with slope $M_{s 1}^{\prime}=-3\left[(\gamma+5)-\sqrt{(\gamma-2)^{2}+7}\right] / 14$.

As a corollary note, the veracity of the original conjecture, that the trial-and-error approach for determining the pellet-surface Mach number. o $_{0}$ becomes less attractive and viable with increasing heating-parameter values $\xi$, can now be elucidated as follows. After choosing, by way of a guess, at tentative value of $\mathrm{M}_{0}$, the trial-and-error method is tantamount mathematically to the numerical integration of differential equation (21). in the reverse. direction, comencing at the pellet surface, where $n=n_{0}=\sqrt[3]{\xi}$, and proceeding towards the sound barrier value, where $n=n_{1}=1$, in the hope of meeting the desired target given as the saddle point. Clearly, the computational effort will increase and the chance of a lucky bullseye hit will decrease as the distance from the starting point to the target grows with increasing values of the heating parameter $\xi$.

One final remark is in order. Determination of the pellet-surface Mach number $M_{0}$ is not an end in itself, but the starting point for the numerical evaluation of various physical parameters, such as $M(\hat{f}), \hat{\rho}(\hat{q})$, and $f(\xi)=\delta_{1}^{\infty} \hat{f}(t)$ dr. For the results presented in this report, these parameters wcre obtained by numerical integrations starting with a predictorcorrector scheme applied to the system of simultaneous differential equa- 
tions (6) and (7). This approach was motivated in terms of convenience and expedience by the ready availability of a directly applicable computer code, which had been established to support an ill-fated attempt to implement the trial-and-error approach of finding $M_{0}$. The authors realize that other avenues, perhaps conceptually and computationally stmpler, could have been taken. For example, use of the suggested technique for determining $M_{0}$ entails numerical knowledge of the solution $M=M(n)$ of the differential equation (21) in the 1nterval $1=n_{1} \geq n \geq n_{0}$ as the result of a numerical-integration process; one could use the same scheme to find $M=M(n)$ also in the interval. $1=\eta_{1} \leq n \leq n_{\infty}$, commencing the numericalintegration scheme once more at the saddle point, where $M_{1}=M_{1}=1$ and $n=n_{1}=1$, with the known slope $M_{s i}^{\prime}=-3\left[(\gamma+5)-\sqrt{(\gamma-2)^{2}+7}\right] / 14$. Upon substitution of $M=M(n)$ into differential equation (16), the function $n=n(\hat{f})$ can be found by separation of variables and simple quadrature; $\sigma(\hat{f})$ is then obtained using equation (13). Finally, determination of $f(\xi)=\int_{1}^{\infty} \hat{\rho}(\hat{r})$ d $\hat{r}$ requires another simple quadrature, and $M(\hat{r})$ is constructed by substitution of $n=\eta(\hat{I})$ into $M=M(\eta)$, i.e., $M(\hat{r})=M(n(\hat{r}))$. 


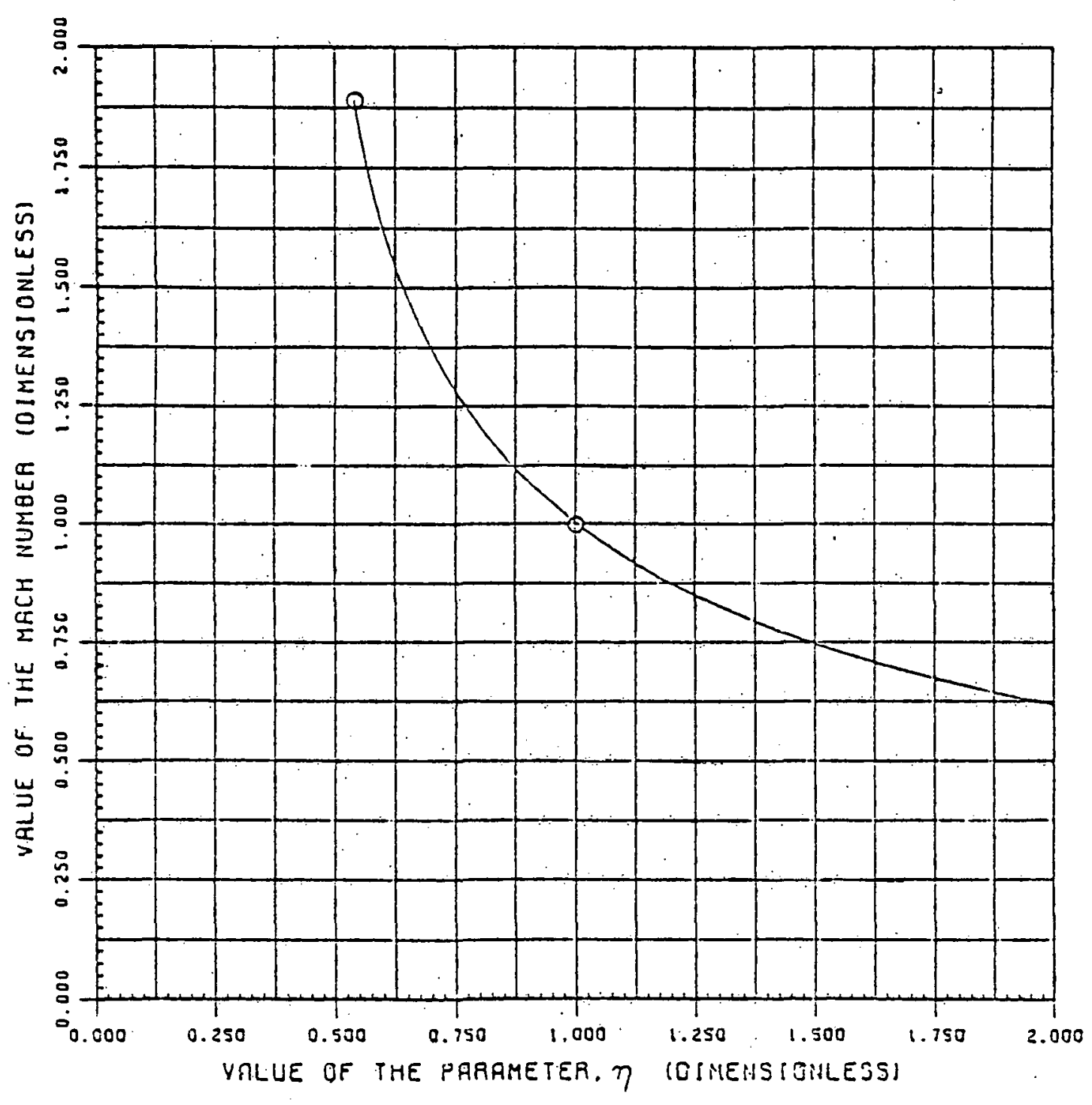

Figure A. Solution of differential equation (21) for the physieally realistic sound-harrier conditions. 
WFPS:TME-79-032

DECEMBER 1979

$U C-20 D$

CONCEPTUAL DESIGN OF A

COMMERCIAL TOKAMAK HYBRID REACTOR FUELING SYSTEM

\author{
KENNETH D. MATNEY \\ HERMANN J, DONNERT \\ KANSAS STATE UNIVERSITY \\ DEPARTMENT OF NUCLEAR ENGINEERING
}

TIEN-FANG YANG

MASSACHUSETTS INSTITUTE OF TECHNOLOGY

PLASMA FUSION CENTER

COOPERATIVE GRADUATE EDUCATION PROGRAM IN FUSION TECHNOLOGY

ADMINISTERED FOR THE. U.S. DEPARTMENT OF ENERGY

BY THE WESTINGHOUSE ELECTRIC CORPORATION

CONTRACT EG-77-C-02-4231-A000 


\section{ACKNOWLEDGEMENT}

This work was performed for the U.S. Department of Energy, under Contract EG-77-C-02-4231-A000, Cooperative Graduate Education Program in Fusion Technology. Reproduction, translation, publication, use and disposal, in whole or in part, by or for the United States Government is permitted.

Special personal thanks are being extended to Dr. Edwin E. Kintner of the U.S. Department of Energy and to Drs. Zalman Shapiro and Daniel Klein of Westinghouse Electric Corporation for their contributions in making this superb program a viable and continuing reality.

During the course of this study, the authors have become deeply indebted to Dr. Z. Shapiro, Dr. D. Klein, Dr. G. Gibson, Dr. E. W. Sucov, Mr. G. Collier, Mrs. E. Iwinski, Mr. J. Easoz, Mr. J. Selembo, and Mrs. Yvonne Harlow of Westinghouse, as well as Ms. T. Gleue, Mr. C. O'Brian, and Mrs. J. Findley of Kansas State University; their contributions, suggestions, and assistance are being acknowledged with sentiments of sincere gratitude.

In addition, the principal author (KDM) wishes to express his appreciation to his two co-authors and advisors (HJD and TFY) for their help, encouragement, and interest in this study.

\section{NOTICE}

This report was prepared as an account of work sponsored by an agency of the United States Government. Neither the United States nor any agency thereof, nor any of their employees, makes any warranty, expressed or implied, or assumes any legal liability or responsibility for any third party's use or the results of such use of any information, apparatus, pronduct or process disclosed in this report, or represents that its use by such third party would not infringe privately owned rights.

Printed in the United States of America Available From

National Technical Information Service

U.S. Department of Commerce

5285 Port Royal Road

Springfield VA 22161

NTIS Price Codes

Printed Copy: A04

Microfiche Copy: A0I 